\title{
Métis Identity in Canada
}

by

Peter Larivière

A thesis submitted to the Faculty of Graduate and Postdoctoral Affairs in partial fulfillment of the requirements for the degree of

Master of Arts

in

Geography

Carleton University

Ottawa, Ontario

(C) 2015, Peter Larivière 


\begin{abstract}
The understanding and acknowledgement of Aboriginal rights has grown in importance within Canada as a result of the ever changing legal landscape and as Aboriginal groups more forcefully confront decades of colonial rule to assert their historic rights. While this has predominantly come out of First Nations issues, there has been a gradual increase in the rights cases by Métis communities. Primary among these was the 2003 Supreme Court of Canada Powley decision which introduced how Métis identity and community identification are key in a successful litigation claim by Métis.
\end{abstract}

This research considers questions surrounding the contentious nature of Métis identity including how Métis see themselves and how their understandings are prescribed by others including the state, through tools such as the Census of Canada. 


\section{Acknowledgements}

There is always a fear in acknowledging the support of individuals who assisted over the years that someone may be missed. So let me thank all those whose paths I have crossed and who in their own way set the stage for my being in this very place at this time. Without you I would not have made it here and I thank you.

There are specific people who I do wish to highlight. My mother and father and my sister and her family all played a role not only in my formative years but continue to be part of my every day. In addition, the Pagé family who I have come to know and love over these last 25 years are a big part of my life.

My colleagues throughout my career in the federal public service but especially Brendan O’ Donnell, Ann Holtz, Darlene Pearson and Nadine Crookes at Parks Canada. I thank you for your patience and support and giving me the opportunities to explore not only new and interesting subject matters but also my own sense of self.

To those whose paths I have crossed throughout my university academic career that started at Carleton University over 30 years ago, to the many professors and staff thank you. Professor Fran Klodawsky whose support and advice has meant a great deal at the late stages of this research a very special thank you. To the thesis board members I thank you for taking time to help me progress in the final steps of the Masters program.

To the elders and community members of Métis, First Nation and Inuit communities who have been my teachers, I offer you my heartfelt thanks and respect. I will always stand with you in the struggle.

Finally I wish to acknowledge two individuals without whom I know I would not be at this stage in my life. Professor Derek Smith, you have been a mentor in more ways than you will ever realize. I know I wasn't the easiest grad student to supervise. Thank you for everything. I know our paths will cross again.

And Joanne, you have been my life. Without you none of this would have meaning or importance. I hope that you know I will always thank you for the time you allowed me to take to do this research at the expense of our time together. You are not only my wife, but my best friend and I will always love you.

I dedicate this thesis to my Grandmother and Grandfather at the church, Ena and Joe Leblanc and my Grandmother and Grandfather at the club, Marjorie and Solomon Lariviere. 


\section{Table of Contents}

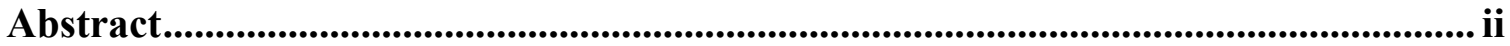

Acknowledgements .................................................................................................ii

Table of Contents ......................................................................................................... iv

List of Tables .................................................................................................................... vi

List of Illustrations........................................................................................................................ vii

1 Chapter 1: Introduction - The Power of Identity ......................................................... 8

$1.1 \quad$ Purpose of Research........................................................................................ 12

1.2 Overview of the Thesis Chapters ............................................................................ 14

$1.3 \quad$ Positionality: From where I stand …………………………………………..... 17

2 Chapter 2: Métis Identity and Community ........................................................ 19

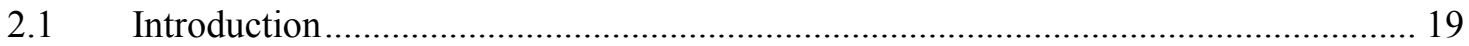

2.2 Identity: Theory and Concepts.......................................................................... 21

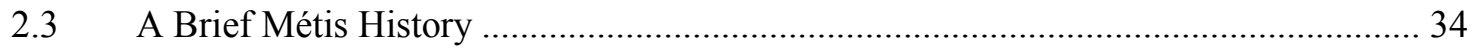

2.4 Métis Identity and the Royal Commission on Aboriginal Peoples .............................. 40

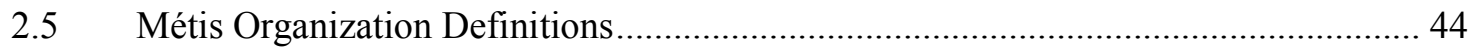

$2.6 \quad$ Concluding Thoughts ............................................................................................... 49

3 Chapter 3: Métis Case Law: Arguing Identity.......................................................... 50

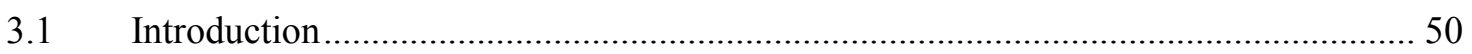

$3.2 \quad$ Powley

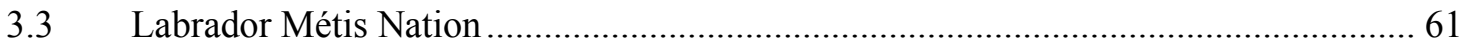

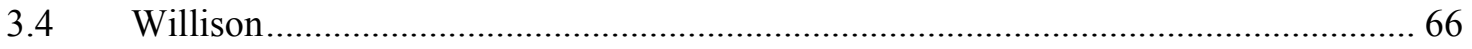

$3.5 \quad$ Goodon

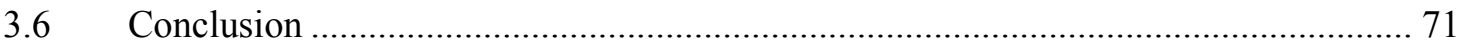


4 Chapter 4: Methodology and Geographic Distribution of Métis Peoples and

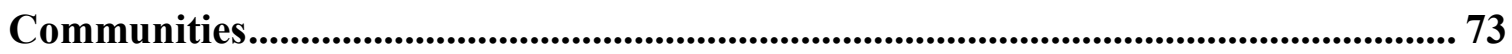

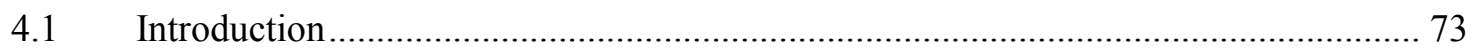

4.2 The Census of Canada - Overview........................................................................... 77

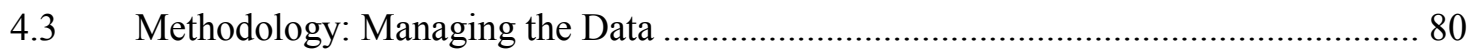

4.4 Census Data: An overview of Census Data ………………………………….... 84

4.5 Mapping and Métis population ……………………………………………….... 93

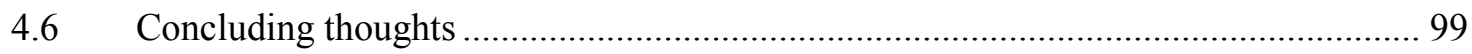

5 Chapter: Conclusion .......................................................................................................... 101

Bibliography or References................................................................................................. 118 


\section{List of Tables}

Table 1 - 2001 Métis population by province 86

Table 2 - 2001 Métis populations in select CSDs 88

Table 3-2006 Métis populations in select CSDs 89

Table 4 - Métis population in select CMA's 91

Table 5 - Largest Métis CSDs 2006 


\section{List of Illustrations}

Illustration 1 - Map 1 - 2006 Winnipeg CTs 111

Illustration 2 - Map 2 - 2006 CSD Métis identity - Hot Spots 112

Illustration 3 - Map 3 - 2006 CSD Métis population normalized by total population - Hot Spots $\quad 113$

Illustration 4 - Map 4 - 2006 CSD Urban Centres - Métis population 114

Illustration 5 - Map 5 - 2006 CSD Métis as percentage of total population 115

Illustration 6-Map 6-2006 CSD Métis as percentage of

$\begin{array}{ll}\text { Aboriginal population } & 116\end{array}$

Illustration 7 - Map 7 - North Bay area Métis Communities 117 


\section{Introduction - The Power of Identity}

In this thesis, identity is considered in two ways: how one sees oneself and how others see an individual or group of individuals (community). As I understand it, when identity is imposed, it often takes on a role of power, with one group imposing an identity on the other (Said, 1979). Whether identity is assigned to subjugate and control or self-prescribed to claim a sense of ownership and authority (de la Cadena and Starn, 2007: 12), identity is a tool that plays a role in the relationship between peoples who may share a common geography but who see a separation or difference from each 'other'. This research looks at the question of identity with a focus on the Métis peoples in Canada, examined through a range of perspectives, including definitions presented by Métis organizations, and through the eyes of the Canadian nation state, both in the form of census data, and through recent court decisions, in particular the 2003 Powley decision by the Supreme Court of Canada. This research, grounded in the concept of identity as socially constructed and contested, demonstrates how Métis identities are shaped by both geography and a range of political processes, including struggles for the recognition of resource rights.

Courts play a central role in legal definitions and the rights of Aboriginal populations in Canada. In 2003, the Supreme Court of Canada (SCC) released one of the most important decisions on Métis rights in Canadian jurisprudence: R. v. Powley, [2003] 2 S.C.R. 207. The case centered on a father and son who had hunted a moose out of season without a license near Sault Ste. Marie, Ontario. The judgment stated that Métis people, like First Nations, have the right to use resources on crown lands. The case and decision set the stage for Métis to take their rightful place alongside Canada's First Nations and Inuit peoples as 
people with historic resource rights, which had been all but denied them until this decision, despite the fact that Métis were legally recognized as part of the broader Aboriginal population in 1982 within the framework of Canada's Constitution (Boisvert and Turnbull, 1992). This denial had been manifested in the federal government's refusal to develop Métis related policy as a federal obligation, leaving it instead to provincial jurisdictions. As Chartrand states,

The added anomaly found in the current federal policy is the political stance that the Métis people are not included within the federal legislative authority derived from section 91(24). $(2002,16)$

Matters related to Métis health, education and other social support, which the federal government has provided to First Nation and Inuit peoples, have been denied to Métis (Friesen and Friesen, 2004). This denial has led to a two tier policy when it comes to Canada's Aboriginal peoples; First Nation (Status Indians) and Inuit peoples fall under federal responsibility, where there is no contemporary or modern day Land Claim that has devolved those responsibilities to the particular community, and Métis and Non status Indians who fall under Provincial authority in matters such as health, social welfare programs and education. Identity then, is not merely a complicated theoretical concept, but one that has significant consequences for people's livelihoods, and more broadly their place within Canadian society. Despite the Powley ruling, however, the question of Métis identity has not been settled. There remains considerable debate and differences in public statements and policies about what it means to be Métis, and this question continues to be highly contested.

At the time of the Powley decision, even the main actors in this case indicated the extent 
to which the SCC advanced the notion of Métis rights was surprising and unanticipated.

The Powley's lawyer, Jean Taillet, a great grandniece of the legendary Métis leader Louis Riel, noted on national radio,

'It's an astonishing thing to me. I had expected that we would get the basics of the affirmation but it's more than that. It's a complete affirmation of every argument we made.' (CBC “The Current”; 2003)

While the decision had much to offer the Métis people, it also left a gaping hole for the federal and provincial governments. Both levels of government would look to each other to take the lead in developing Métis policy and legislation as well as ensure that any new policy development did not impact Métis asserted rights without justification. In January 2013, the Federal Court ruled on the long awaited CAP-Daniels Case (Daniels v. Canada (3013 FC6) T-2172-99. The case effectively ended the debate, albeit temporarily, by ruling that Métis were Indians for purposes of 91(24) of the Constitution Act 1867. This then places responsibility for Métis within the legislative authority of the federal department of Aboriginal Affairs and Northern Development Canada. The federal government appealed the decision and recently in the spring of 2014, the Federal Court of Appeal upheld the decision as it pertains to Métis. The CAP-Daniels decision by the Federal Court and recent decision on appeal by the Federal Court of Appeal, effectively dealt with this very issue as Métis would be Indians under the Indian Act and therefore have access to the same programs and services that are available to Indians under the Indian Act and other federal legislation and policies. Expanding on this, policy makers will need to respond to two fundamental questions: Who are the Métis and where are contemporary Métis communities located?

There are important connections between geography and Métis identity given the fact that 
there are Métis peoples with different histories living across the country and the fact that connections between individuals and communities is a common litmus test for identifying who should be able to claim Métis rights. As Giokas and Chartrand explain,

Proof of Aboriginal rights requires proof of continuity between a contemporary and an historic Aboriginal community, not proof that an individual is descended from an historic individual. Aboriginal rights are not inherited by individuals, like personal property; nor are they inherited as genetic traits according to racist notions. A community is a social and legal fiction maintained through generations by social institutions. A successful defense based upon an Aboriginal right requires proof of membership in the Aboriginal community in which the Aboriginal right is vested. $(2002,111)$

Identity, including Métis identity, is also conferred in Canada using census data tied to specific geographic areas. While useful for certain purposes, there are serious limitations to the utility of census data, even though they are based on self-identification, as opposed to imposed criteria. An assessment of the census for counting and mapping Métis populations - in relation to other definitions - can help with the interpretation of what the numbers say, and do not say or how those numbers may be manipulated. A critique may also offer better alternatives for data collection that provide information for social services and policy development while not imposing problematic, politically charged and what some have called racialized narratives on the "Métis question" (Anderson, 2014: 4).

It is important to point out that different Métis organizations have also made public statements about Métis identity. As discussed in the next chapter, there are important differences between their stances, in accordance with different, often conflicting political agendas. For example the Métis National Council (MNC) sees Métis identity tied to the historic Red River Métis communities. The Congress of Aboriginal Peoples (CAP) has a 
much broader geographical coverage for Métis which encompasses the whole country and is not limited to a direct link with the Red River settlements. These conflicting approaches have sometimes placed Métis communities with a shared history and overlapping traditional territories in direct conflict with each other, showing again how identity is often contested and political. Defining who is or who is not Métis is a contested and complicated task, and one that can have serious, practical consequences for individual people and for communities. It also leads to the possibility that the identifier is assuming a role of authority of the identified and using that authority to control the consequences of the identity.

Questions of identity are an extremely sensitive and politically contentious subject. Identity, whether religious, or cultural, has been at the root of wars and genocides and continues to this day to be a subject used more to separate people from each other than unite them. As Said states in his classic book Orientalism,

Ideas, cultures, and histories cannot seriously be understood or studied without their force, or more precisely their configurations of power, also being studied. (1979, 13)

Métis identity in particular has many twists and turns as competing interests impact on not only who Métis are but also how Métis see themselves in relation to other Canadians. Métis organizations, the courts and statistical agencies all play important roles in this complex, ongoing process. Many questions remain unanswered, and further research can provide insights that are needed to understand the issues and formulate better policies.

\subsection{Purpose of Research}

The broad goal of the research presented here is to compare divergent world views as 
applied to the concept of Métis identity. More specifically, the purpose is to examine the clash over how "Métis" see themselves as compared to how the Canadian state represents and defines the Métis at the national scale. The research is guided by three primary questions. First, what are the key planks of Métis identity, as put forth by Métis organizations, and are there significant differences among them, based on geography? Second, how does the state interpret Métis identity through the lens of census data and through court decisions, and what are the implications for Métis people and their rights and place within Canada? Third, what is the role of community in the interpretations of who can be considered Métis? The research demonstrates that state definitions of Métis identity are extremely limited in scope and represent a neo-colonial approach of ethnic labeling that undermines the political agency of Métis peoples. While the census can be used as an overview tool, it attempts to create a single Métis population, ignoring the uniqueness of different Métis communities that could be used and recognized by the courts to establish Aboriginal land, resource and other rights.

In looking at the research more specifically, the objectives are to,

- Provide a comparison and analysis of alternate definitions of and ways of thinking about Métis identity

- Assess the role of regional differences and the importance of place and community in identifying Métis populations.

- Assess and critique the utility of census data as a way to help identify Métis communities. 
Finally this research also discusses internal divisions among people who claim a Métis identity, and whether some claims are done as a means of, as Circe Sturn refers, 'raceshifting' (2002) or as 'ethnic drift' (Guimond, 2003: 96) as a way to take advantage of newly acquired rights.

Fulfilling these objectives will bring to light new opportunities for better understanding questions of identity related to Métis and make explicit the value and limitations of using a geographic approach to interpret the quantitative distribution of those who self-identify as Métis across Canada, particularly in relation to court decisions on matters of identity.

\subsection{Overview of the Thesis Chapters}

This thesis is comprised of five chapters, which are described below. Chapters 1 and 5 provide an introduction and conclusion to the research. With chapters 2, 3 and 4 each can be seen as a self-contained piece of the whole. Through the analysis of identity in chapter 2 , the analysis of court cases which manipulate and adjust the notion of identity in chapter 3 and finally the quantitative process of using census data to map identity in chapter 4 , the chapters together present the conceptual underpinnings of the research, the presentation of evidence, and analysis of the research data. 
A brief synopsis of the content of the following chapters follows:

Introduction - As identified in this introduction, a discussion of the research, goals and purpose as well some fundamental background is covered at a general level as it is required for the telling of the Métis story.

Chapter Two - Métis Identity and Community: Here the thesis explains the issues surrounding identity in general and Métis identity more specifically, drawing from the ideas of Edward Said and others. The chapter describes and analyzes different definitions of Métis identity, some imposed and others created by Métis political organizations, to show how Métis identity is 'created' through self-identification; as part of a community, grounded in a common history as a group see themselves; and through imposed identities, where the state or other actors create an 'us and them' dichotomy to differentiate a group of people as different from themselves. A brief Métis history provides background that informs how Métis identity is perceived by both Métis and the nation state.

Chapter Three - One People or Many Peoples: Métis Case Law and its Implications for Defining Who is Métis: Using concepts of identity this chapter looks at how Métis are defined within the legal system. The discussion focuses on the major court cases that affect Métis rights, including the watershed R. v. Powley case of 2003, and three others that followed. As I explain, these cases have played a significant role not only in how the Crown sees its legal obligations when working with Métis issues but also in how the Métis see themselves. All contemporary writings on Métis identity incorporate the Powley decision in some way. This necessity to provide a synthesis of these cases is important as a basic 
step in understanding the Métis issues in the context of the nation state and the power position of the state over Métis peoples. These cases also form the public storyline of who the Métis are.

Chapter Four - Demography and Geographic Distribution of Métis Peoples and Communities: This chapter examines how census data can be used to better understand the distribution of Métis communities and also how data collection of this type can be used to further neo colonialist aspirations of a nation state through tools which at first glance may seem benign. Further I use this chapter to explore the merits of a research activity that could potentially water down the definition of Métis identity to a point where it is of little or no value. In addition analysis of whether census data may be used to identify contemporary Métis communities is carried out.

Chapter Five - Conclusion: The conclusion discusses the broader implications of the research and attempts to offer alternatives to how Métis may be able to identify themselves as well as considerations on how to approach those other Aboriginal peoples in Canada who may not be comfortable with the label "Métis." It will also reflect on the value of geography as a tool for the courts in making informed decisions. 


\subsection{Positionality: From where I stand}

I want to briefly enter into the issue of positionality and how this research was approached from numerous factors that make up who I am while at the same time trying not to enter into the world of 'Naval Gazing' as Sultana puts it (Sultana, 2007). First and foremost was my identity as a First Nations person, and more specifically as an Anishnabe person. While I am a descendant of a number of cultural groups, it has been my upbringing and teachings as an Anishnabe that has created the person I am. This is not to deny the other heritages that are part of my family tree, but only to recognize how my spirituality, morality and thinking has been molded to a greater degree by one prominent ethnicity. This research, and the tone found in these pages, has been shaped by this history and identity. Another important consideration in this research is found in my role within the public service of Canada. While I have retained my desire to be unbiased, even though the tone of the language in these pages has been critical of the government, it is possible if not probable that the language in this research has been muted. This is not to suggest that a level of concern exists over being free to write a research paper such as this without fear of reprisal. I have enjoyed a long career as a federal public servant and have witnessed significant improvement in the lives and rights recognition of Aboriginal peoples over the period of nearly 25 years. It was through contacts with the department of Aboriginal Affairs and Northern Development Canada that the concept of this research was born and then interest in seeing research completed to ensure better design of policy and legislation that would benefit Métis peoples across Canada was encouraged from a number of sources within the federal government upon hearing of my research. 
Finally my personal experience in working with Métis communities across Canada has equally played a role in this research. In explaining the research to one Historic Métis Nation Elder she replied that she knew I would be engaging in important research of benefit for all Métis and that she appreciated my attempts at not limiting who Métis are to the Historic Métis Nation. That said she also pointed out that the only place where Métis exist in Canada is within those Historic Métis Nation Communities. More on this last point will be presented in the conclusion to this research. 


\section{Chapter: Métis Identity and Community}

\subsection{Introduction}

In considering the approach for writing this research paper one idea became clear. Without a firm grasp on the basic concepts of identity, moving forward and speaking about the specifics of Métis identity would be difficult at best and open to critique. Identity is complex and contested, and there are multiple ways that it can form and be applied to people. Identity can highlight how a people see themselves, and it can also be shaped and defined by the predominant society either with respect or as a representation of the power dominant societies in neo-colonialist environments have over Indigenous communities. Authors who have studied the question of identity, and Métis identity specifically, have done so from a number of different standpoints, whether from a Eurocentric position or from a specific Métis historical position. Giraud (1937) and Stanley (1936) were the first academics to seriously consider Métis identity and history beyond a cursory analysis. But in this case that identity was tied to the historic Métis Nation and the Red River as well as from a period in time when academia was seen as less enlightened on matters of Indigenous issues (Tuhiwai Smith, 1999: Turner, 2006). Others such as Martin Dunn (1994) expanded the study to consider Métis in the Central and Atlantic Canada regions, while Tim Borlase (1994) and David Zimmerly (1975) studied the Métis community of Labrador. Other significant scholarly work on Métis and Métis identity can be found in the work by Peterson and Brown (1985), Diane Payment (1990), and Richard Slobodin's important research on Métis identity in Canada's North (1966). Finally, edited volumes by Chartrand (2002) and Adams, Dahl and Peach (2013) have provided a broad analysis of the question 
of Métis identity within Canada.

In the case of Métis identity, the term has been used as both a general concept that refers to people of mixed race, that being Aboriginal and non-Aboriginal, irrespective of the cultural groups of either, as well as the name for a specific community with a clear history and sense of self. This becomes a very confusing point as Peterson and Brown note in their discussion on the use of the capital ' $M$ ' or lower case ' $m$ ' when identifying Métis (Peterson and Brown, 2001: 6). For their research the capital ' $M$ ' used to denote the Métis Nation, found in the specific area of Western Ontario through the prairie provinces and northern United States which border these provinces and the lower case ' $m$ ' used to denote the inclusive category of mixed race people (Peterson and Brown, 2001: 6). It is important to highlight how identity can also be imposed by others as a means of controlling a population. This will be further explored in this research, using Edward Said's concept found in his groundbreaking work, Orientalism, and more specifically the notion of 'other' and power and adjusting it to the Métis identity question of this research.

In order to examine how the use of the term Métis as identity is used in different contexts, this chapter is composed of three related parts. I begin with a discussion of identity as a concept and how it can be established. I then provide an overview of Métis history, followed by an examination of different ways that Métis identities are constructed by different actors. Finally, I discuss Métis community as a basis upon which Métis identity gains its legal authority, which in turn establishes the validity of Métis rights to harvest and undertake other activities intrinsic to the Métis culture but which normally would be 
regulated by governments. Together these approaches provide a multifaceted view of the different ways of understanding Métis identity, from different perspectives, and how Métis people or more appropriately peoples, interrelate with the nation state that is Canada. As part of this, I look at how others, including Métis organizations, attempt to define a community that may escape what could be a simplistic branding exercise to acquire recognition of rights as determined by the courts. Edward Said's concept of Orientalism is of particular relevance in trying to understand the interface between Métis identity and the power of the nation state.

\subsection{Identity: Theory and Concepts}

What is identity? It is simple to look at this as nothing more than a dictionary definition but identity is a very complicated concept. It is based on at least three possible creation premises (Bowne and Colchester 2002, Lawrence 2003, Sawchuk 2001, Weaver 2001).

The first is the identity one takes for oneself. Who one is and how that individual's history speaks to who they are in the larger context of a local community or even as a global one.

As Roosens notes in the work of the noted scholar Fredrik Barth,

Barth pointed out that an ethic group is, first of all, a form of social organization in which the participants themselves make use of certain cultural traits from their past, a past may or may not be verifiable historically.

Barth points out that the intensity with which a group profiles itself as an ethnic group, and with which individuals stress their ethnicity, generally increases when there is intense spatial-geographical and social contact between groups. The most isolated "traditional" group of people is probably the least ethnically defined. $(1990,12)$

I identify myself in a various array of forms and definitions each dependent on the situation and context I am in. But I argue it goes beyond simple labels to something greater and more 
profound, in line with Martin Heidegger's thesis as described in Being and Time, published in 1953. Identity in the Heideggerian form is an essential part of one's being in the present. It is all those things that go into making a person a truly unique individual. Heidegger's sense of being is in effect speaking to the idea of identity. However, self-identity can be restricted when the state becomes involved. When completing a census questionnaire, my identity is restricted to what is put on offer by the designers of the questionnaire. In this way Isin and Wood see identity as a creational component of cultural politics (Isin and Wood, 1999; 14).

Identity, then, is more than ethnicity, although this piece is central to Métis people and many other distinct groups. Identity is also about being different from others. Coates discusses this through analysis of Edward Said's work,

The issue of identity is crucial, for it speaks to the expectations of social groups, the prevalence of stereotypes within society at large, and the social pressures impinging on individual Indigenous peoples.

Edward Said, in his now seminal work Orientalism, argued convincingly that the cultural identity of the "other", or non-European, was largely an artifact of European colonialism. Subsequent authors, many working from a more empirical base than the writings of Said and his followers, have demonstrated the process by which the concept of "Indian" was very much a creation of newcomers. $(1999,24)$

This notion of a distinct identity for Métis peoples is important from two points of view. First the Métis see themselves as different from their First Nation cousins. While they may share a related history with one side of their collective family tree, they also have developed and fostered a truly unique and separate cultural identity from either of their two founding histories. They are thus neither "Indian" nor EuroCanadian. 
A majority of archaeologists and historians who have studied Métis society characterize it as a "hybrid" culture, one that integrates European and native characteristics (Anick1976; Giraud 1986b; Elliott 1971; Doll, Kidd and Day 1988). This categorical approach defines the Métis as a collection of traits and styles and assumes that as those traits and styles change, there is a correlative change in Métis ethnic identity. The fallacy of this perspective becomes apparent when one attempts to identify spatial and other patterning in the Métis data and carry on discussions with Métis informants. Therefore, it became necessary to reappraise many longstanding theoretical arguments on ethnicity, the meaning of style, acculturation and related issues. Métis ethnicity involves a host of intangibles including a sense of common identity found on and strengthened by historical events of the $19^{\text {th }}$ century. More importantly, Métis ethnicity envelopes a shared way of doing things that is regulated by unconscious rules and principles. To understand the Métis as an ethnic group, one must come to grips with this underlying phenomenon. (Burley, Horsfall and Brandon, 1992: 2)

Another important component of identity is that it is shared by more than one person, by a group of people who have something in common and who are different in some way. Identity creates a sense of home and a complex feeling of inclusion with a group of individuals with whom you share a related history (Roosens, 1990: 16). Belonging to a community is often an important factor in creating a common sense of identity. The sense of community can be expressed through the collective identity and portrayed through the use of terms such as nationhood, people hood, or tribe.

Finally identity may be created, and the circumstance under which it is created (such as when it is imposed by others) needs to be considered to understand Métis identity. Sawchuk writes "An imposed identity rarely provides as effective or spontaneous a means of political organization as a self-proclaimed or self-developed identity does" (Sawchuk, 1991:71). Sawchuk's view is that this form of identity creation is about government control. It is situated within the post-colonial or neo-colonial theoretical world and whether seen as a positive form of identity recognition, or as negative form of identity creation, its creation 
by an imperial power or central government and not by people themselves signifies control and power.

Edward Said is a postcolonial scholar who had a tremendous impact on how we understand the relationship between power and identity. While Said concentrated his writing on Western imperialism in the near east, the area of the globe also referred to as the Orient, his ideas are relevant for the Canadian context as well. Said's contribution to the understanding of the 'Other' reveals how power inequalities shape identity and can provide guidance toward more equitable and respectful ways of understanding cultural difference. The 'Other' as described by both Edward Said and Frantz Fanon refers to the racialized fabrication of ethnicity produced within a colonialist system. But it is to Homi Bhabha that there is a clear indication that the 'Other' is tied to power and the colonial discourse (Bhabha, 2007: 95)

The power of creating the other can also be constructed in court decisions, as an authoritative element of the state, and one that reflects the perspectives of the predominant society. This is what Said refers as the author's "strategic location" a concept that situates the court within a certain point of view that shapes their interpretation as they are situated in a 'place' other than that which is a 'Métis place'. As Said explains,

Orientalism can thus be regarded as a manner of regularized (or Orientalized) writing, vision, and study dominated by imperatives, perspectives, and ideological biases ostensibly suited to the Orient. The Orient is taught, researched, administered, and pronounced upon in certain discrete ways. (1979: 202)

This will be further discussed in subsequent sections of this research. 
These points are directly played out in Métis studies in a way that could see the word Orient changed to Métis above and receive the same degree of importance. From the early histories of Métis such as those by Giraud (1984), Stanley (1992) and Morton (1973) to the later works which have included scholarship by Métis authors such as Anderson (2008, 2011), Goulet (2006) and Adams (1994), the construction of the other in a way that creates a dominant, simplified image that Said speaks about has similarly lead to a romantic, oversimplification of the Métis as a single people that has been accepted and reinforced by the nation state.

The writings of Edward Said go far beyond what is presented here. His work shows that Métis identity can be critically analyzed and understood in ways that are not unique in the history of the world. Through Said's work, we can show those that have influence and more control, see the 'other' in a manner that maintains and enhances their power for as long as possible.

With control by the nation state over the political and cultural future of Métis through the use of a separate identity from that of the larger community population, the nation state can categorize people into various divisions that maintain its perceived power over others. This notion of identity leads to a separation or distancing from the other, a form of us and them. For Métis people, identity is as much self-ascribed as it is prescribed by others (Sawchuk, 2000) In his article 'Negotiating an Identity', Sawchuk states,

not all expressions of ethnicity are self-defined. In its relationship with Native peoples, the nation-state often creates or defines Aboriginal identities for its own use (2000: 73) 
This type of imposed identity has occurred in the case of the term 'Aboriginal,' which entered into modern Canadian language as a legal identifier which came into everyday usage as the result of section 35 of the 1982 Constitution Act. Until that time, First Nations or "Indians," Inuit or "Eskimo" and Métis were commonly identified separately, and often individually (e.g., Mohawk, Wendat, Haida) and not as a single group under a shared label, which some argue lessens the uniqueness or distinctiveness of the Métis. In fact, as a result of the appearance of the term Aboriginal in 1982, as a public servant at work, I've observed that most public documents created by government no longer use the terms Inuit, First Nation or Métis but simply “Aboriginal” regardless of the application or purpose, and even for documents that are clearly aimed at only one of the three categories included in the term.

It is equally disconcerting to hear reports on Canada's national broadcaster, the $\mathrm{CBC}$, generalize by using the term Aboriginal even when speaking about a specific community (e.g., Algonquin or Kitigan Zibi, Mohawk or Akwasasne, etc.). It should be noted that this tendency has resulted in a backlash in many First Nation communities where elders are demanding governments and others address them by their proper names as nations and not within some universal, homogenizing identifier. I have witnessed this on many occasions in my role as a federal public servant. Today it is common when meeting a First Nation community to offer a verbal recognition of that community's historic ties to the traditional territory upon which it lives, including federal lands which may be contested places in terms of occupancy and use, by that First Nation community. 
It should be noted that the 1982 Constitution Act did not define the term Aboriginal beyond identifying who made up Aboriginal Peoples in Canada. The Act reads as follows,

35. (1) The existing Aboriginal and treaty rights of the Aboriginal peoples of Canada are hereby recognized and affirmed.

(2) In this Act, "Aboriginal peoples of Canada" includes the Indian, Inuit and Métis peoples of Canada.

(3) For greater certainty, in subsection (1) "treaty rights" includes rights that now exist by way of land claims agreements or may be so acquired.

(4) Notwithstanding any other provision of this Act, the Aboriginal and treaty rights referred to in subsection (1) are guaranteed equally to male and female persons. (Canadian Constitution, 1982)

As Métis were not defined specifically, it may be seen as an open door for uncertainty as to who was meant to be included as Métis as people with Aboriginal rights (Chartrand 2002).

Chartrand states,

Section 35.1, which was added in 1983, emphasized the distinct political character of the aboriginal peoples, and their unique constitutional status as groups entitled to participate in future consultations on constitutional amendments.

In a sense, however, section 35 represents an empty shell for the filling. It contained no definition of either the aboriginal peoples or of the rights that were the subject of constitutional recognition. (2002: 28) 
And continuing,

The Charlottetown Accord did not include a definition of the Aboriginal peoples, but a separate Métis Nation Accord reached between the federal government, five provinces, and the Northwest Territories would have defined the Métis nation as the historic "nation" of the North West. (Chartrand, 2002: 30)

While who was meant to be included as Métis was clear for Chartrand, for others, particularly the community affiliates of the then Native Council of Canada, now Congress of Aboriginal People (CAP) the National Aboriginal organization whose responsibility was that of Métis and Non-Status Indians, the definition of Aboriginal was self-evident in terms of identifying the three groups in the most broadest application possible.

However, without being defined, if the term Métis is understood as referring to a group of people located in one geographic area, namely the Red River region of Western Canada, then where does that leave other peoples who shared a similar ethnogenesis but whose identity is tied to some other place?

There has been some debate as to who is covered under the term Métis in the Constitution Act 1982 by authors such as Sanders who writes:

That political consciousness [of Métis communities] never developed in northern Ontario, northern Quebec, British Columbia or the present Northwest Territories. The Métis political reality, to which the federal government was responding, was limited to the present Prairie Provinces. (1979: 15)

The grouping of the Métis with First Nations under the label Aboriginal may be convenient for government agencies in some ways, and represents an important recognition that Métis people have historic rights, but it also potentially leads to confusion. Paul Chartrand, who 
looks at the issue in even greater detail not only in terms of the Constitution Act 1982 but also by looking at how Métis fit into the original Constitution Act 1867 under s. 91(24), states:

It is not partically [sic] helpful to reach the conclusion that the Métis are included as "Indians" in section 91(24) of the Constitution Act, 1867 if the identity or definition of the Métis community is not known.

More than two decades later, the Supreme Court of Canada weighed in on the debate in the 2003 Powley decision of which more will be discussed in the following chapter. For now it is important to highlight what the courts said in terms of whom they felt were the Métis people as identified in the Constitution Act. The court wrote,

The term "Métis" in section 35 does not encompass all individuals with mixed Indian and European heritage; rather, it refers to distinctive peoples who, in addition to their mixed ancestry, developed their own customs, way of life, and recognizable group identity separate from their Indian or Inuit and European forebears. (SCC, 2003: 208)

There is much more to cultural identity, however, than legal definitions. As noted earlier, identity is a social question that occupies much of the cultural debate in Canada. Northerner/Southerner, French/English, the Quebec question - all have their roots in peoples' attempts to identify themselves as unique or different from another. On the specific issue of Aboriginal identity Coates states,

Identity and membership are social constructs, with legal and political overtones. They have become contested territory between Aboriginal and non-Aboriginal peoples and within Indigenous societies (1999: 37).

Métis identities are no exception. They are contested territory within Canadian society. A further consideration is that Métis people are not only marginalized (Adams, 1999) by the non-Aboriginal population but they are also at times subject to views by First Nation 
peoples that seem to question their historic rights and legitimacy. As an example, at a law conference in November 2003, representatives from various First Nations from across the country objected to the Crown's consideration that Métis peoples had Aboriginal rights identified in the Powley decision (Pacific Business and Law Institute Conference, Toronto: Nov $20 \& 21,2003)$. The simple fact may be that First Nation peoples see limited resource availability being made to them and are concerned that additional resources will not be made to cover the expansion of the "Aboriginal" population. As the Report of the MLA Committee on Métis Harvesting states,

First Nations groups were respectful of legitimate Métis individuals exercising their harvesting rights, but expressed concerns that the Agreement exceeded the Powley decision and has ignored the site-specific aspect of the decision. First Nations groups complained that they were not consulted about this agreement prior to it being implemented. First Nations groups feel that the current Agreement may have potential to infringe upon their treaty rights.

and further in the report,

Accordingly, Alberta must exercise diligence when granting Métis rights to individuals to ensure that the rights of First Nations' members are not compromised. (Province of Alberta, 2006)

For First Nation communities this not only includes financial and economic development assistance but also access to traditional territories for harvesting activities that are already being curtailed in favor of resource development. This was seen in the request for intervener status by the Blood and Siksika First Nations in the Hirsekorn Métis Rights Case in Alberta in 2011.

The ability of Métis communities to exercise land rights based on their cultural identity, under law, is dependent then on the historical point when the Crown could be seen as 
maintaining a level of authority through political and legal control of a territory. As Teillet notes,

In Indian rights claims, part of the test requires that the claimant prove the practice, custom or tradition was exercised at the time of contact with EuroCanadians. For Métis the time test is "effective control", which is the time when Métis customs, practices and traditions were changed by the influences and control of Euro-Canadians. (2012: 345)

There is too much at stake politically for Métis to be defined in terms that may lead them outside of the available legal protection of section 35 of the Constitution Act 1982. More precisely, with the ability to define themselves as individual distinct nations located within specific geographic territories, Métis communities could approach the issue of Métis rights and title on a "one off" basis. The risk would be especially high should a court case arise as a result of a community's application of its asserted rights over harvesting and land title and subsequently lose the case and their rights by an unfavorable decision as occurred in the Hirkeshorn (Alberta, 2006) and Blais (Manitoba, 2003). The federal government has equally side-stepped trying to define the term Métis and who is legally encompassed within this term. The courts, in particular the Supreme Court of Canada has provided some guidance by linking Métis identity to historic communities, but it is not a clear-cut definition, so we are left in somewhat of a vacuum. But this is not necessarily something that can be resolved in a satisfactory manner. While definitions are sought for legal purposes, the imposition of definitions remains problematic and subject to potential abuse by political elites with their own agendas. In addition, as Arthur Ray points out, the courtroom, for him, was like a classroom and the judge the student (Ray, 2011; 145). He goes on to state, 
Even though some judges I addressed were familiar with aspects of local community history (which seemed to be the case in all the Métis trials), none of them knew much about the complex ethnohistory that was relevant to the case before them. (Ray, 2011: 147)

This lack of fundamental knowledge likely results in a more favorable position for the Crown since its burden of proof is limited to the facts of the case while Métis defendants (as well as First Nation and Inuit) are forced to provide a more extensive base layer of knowledge prior to dealing with the immediate facts of a case. As much of this base layer is based on oral history, the application in a court with a western bias will likely not be given the same weight as evidence provided through a western lens.

More than any other question not asked or issue not brought up in the Powley 10 part test, is the question of how to define who is Métis. This test, which will be more fully explained in the following chapter, provides a set of specific criteria linking factors to determine the validity and applicability of a Métis person or community engaging in traditional activities such as harvesting. While the Supreme Court of Canada ruled on the issue, it clearly avoided entering into any formal discussion of how the use of the word Métis is employed in public policy or how it is used by the Métis themselves. Further, if the courts, and specifically the Supreme Court, would have broached the subject of identity, it would have placed the National Métis organizations and the Provincial and Federal Crown in a position to finally resolve the issue (Wilson, 2008:35). This was the same issue raised in the 1996 Royal Commission on Aboriginal Peoples (RCAP, 1996: 200). 
Another significant area in which Métis identity was developed by the nation state is within section 35 of the Canadian Constitution. I would argue that a pan Métis identity was created within the ambiguity of section 35 and the blame falls squarely on the drafters of section 35 of the Constitution Act 1982 which created limited and narrow options on the term Aboriginal by not allowing for other Indigenous peoples of Canada an opportunity to assert their rights within the meaning of the Act who do not fit neatly within the Inuit or First Nation categories.

Giokas and Chartrand (2002) ask the question 'Who are the Métis in section 35?' In answering this question they state,

A recent study revealed confusion about Aboriginal definitions, shifting identities over time, and a wide range of functional definitions used by government departments and organizations dealing with Aboriginal people.

The term "Métis" is generally viewed in Canada as referring to "in-between peoplethose within neither of the two racial categories of Indian or White. Hence we have the English term "Half-breed" - half this and half that, and not enough of either to move into one or the other category. (Giokas and Chartrand, 2002: 84)

And continue,

As the foregoing passage notes, the central problem is that "the term Métis has been used in different ways at different times." Three of the ways in which the term has been used over time are mentioned. They are:

1) Associating English and French mixed-ancestry groups (from Rupert's Land) as if they were the same group;

2) Including other mixed-ancestry persons whose origins may have been far removed from the Red River and Rupert's Land Métis Nation;

3) Referring loosely to persons of mixed ancestry who may never have had Indian status, or who, having had status, may then have lost it through the status and enfranchisement rules in the Indian Act. (Giokas and Chartrand, 2002: 85) 
This demonstrates that within the academic community, Métis identity is not seen as a single all-encompassing term similar to that of Inuit, but instead that there needs to be a new understanding of those Métis peoples not captured under a single history and how they too may be Aboriginal in terms of holding sui generis or unique rights within the Canada. This confusion however is not new and is an issue I will now explore.

\subsection{A Brief Métis History}

Understanding any cultural community without some idea of where the community came from is like reading a book without first having read the preface and introduction. However, while a synthesis is needed to provide some background on the history of the Métis, there can be no single story. Different scholars have told different stories from their own unique perspectives. In this section I attempt to provide a broad historical overview, while recognizing the varied histories of the peoples who refer to themselves, or are referred to by others, as Métis. In the case of the Métis, certain commonalities exist, specifically around the ethnogenesis of the Métis that is found in colonial encounters. At the same time, there are significant regional differences that exist today that are rooted in different histories.

As there is no single Métis people, there can be no single Métis history. This has been recognized by historians, sociologists, anthropologists and others for many years but has received more attention following the 1982 repatriation of the constitution. Historians and other scholars such as Richard Slobodin (1966), Antoine Lussier (1985), and Jacqueline Peterson and Jennifer S.H. Brown (1985) have been joined by others, such as Brenda Macdougall, Carolyn Podruchny and Nicole St-Onge (2012), all of whom have dealt with 
the sometimes difficult task of providing a general explanation of Métis genesis while not ignoring the varied "mixed race" communities who identify as Métis but who do not fit easily into the dominant narrative. At the same time, those involved with Métis research identified above have struggled to clearly articulate the historical and cultural connections that must exist for a diverse group to be clearly identified as belonging to a single Métis population. The June 2013 report by the Senate Standing Committee on Aboriginal Peoples highlights this effectively by stating the following,

The committee was privileged to hear and learn from Métis witnesses about their histories, cultures, and experiences... The evidence heard was extremely interesting, valuable, and often eye opening, as issues relating to Métis identity are not generally well understood outside of these communities. (Senate of Canada, 2013:2)

It should also be noted that in addition to this report, one of the most significant responses to Aboriginal issues and Métis issues in particular by the federal government, the 1996 Royal Commission on Aboriginal Peoples, held the same view as to the difficulty in summarizing a single Métis history, in recognition of the diversity of Métis communities that are found across the country (RCAP Vol 4 1996: 255). The Royal Commission report even went as far as highlighting that along with the Red River Métis who would be those peoples more typically identified as Métis (the historic Métis Nation), there are separate Métis communities found in Labrador, the Maritimes, Quebec and Ontario (RCAP Vol 4 1996: 255). In general, if such a diverse group of peoples could hold a general history common to all, with timelines that align with the early establishment of commerce through trapping, fishing and other activities which introduced Europeans into the territory of the First Nations, the origins of the Métis people emerge out of two important steps. The first is from the union of a people of Euro-Canadian ancestry and First Nation or Inuit ancestry. The second is the development of one or more unique cultures among the descendants of 
these unions that did not fully integrate with the cultures of either tradition, or one that was simply a combination of the two cultures. This genesis of a new identity has resulted in the development of what appears to be six different Métis histories across Canada (for Labrador, the Maritimes, Quebec and Eastern Ontario, Red River/Prairies/North Western Ontario/Mackenzie District, the Great Slave Lake region of the Northwest Territories, and the area west of the Rockies primarily in the Fraser River area) (RCAP Vol 4, 1996; Lussier and Sealey, 1980; Slobodin, 1966; Peterson and Brown, 1985; Wilson and Mallet, 2008; Bouchard, 2006). This challenges the common assumption of government agencies that there is a single Métis population.

Another common thread that weaves through most of the Métis groups today is that their histories are closely tied to the fur trade. While not a requirement for a group to claim Métis identity, the fur trade was of critical importance for providing opportunities for Euro(Canadian) men and First Nation and Inuit women to come into regular cultural contact and develop unions beginning in the seventeenth century, an encounter often referred to as 'la façon du pays' (Payment, 1990: 19). This expression implies that such unions were based on basic economic and social ties between the Aboriginal and nonAboriginal people that enhanced trade. These relationships were temporary for most men, many of whom would simply return to their home countries once work was completed, abandoning their relationship and the children who were left behind as members of their mother's culture and community. But while common threads may seem to link the different communities that today unite under a single name as part of their public identity, the establishment of rich and important Métis communities, not as First Nations and not as EuroCanadians, is a diverse combination of situations that formed these unique peoples. 
In trying to answer how the genesis of a Métis people came about a number of scholars have provided their best guess as to the form that this genesis took. Authors such as George Stanley (1936), Arthur S Morton (1939 and 1978), Diane Paulette Payment (1990) and others have attempted to define a creation story of the Métis in a manner that could highlight a set of characteristics which led Métis to define themselves as a distinct people in comparison to their EuroCanadian and First Nation ancestors. But it is Payment's description of what may best be described as the genesis moment and early historical period of resistance that is particularly helpful for understanding contemporary Métis identity. Speaking specifically of the Red River Métis she notes,

The Métis developed a national consciousness and acquired cohesiveness as a group during these years. Under the leadership of Cuthbert Grant, they rose in armed protest against economic sanctions on the sale of pemmican imposed by the Hudson's Bay Company. (Payment, 1990; 21)

From Payment's brief description we can pull out the possible triggers that created this unique sense of identity. First, there was the development of a national consciousness. This sense of nationalism would have created something apart from the larger communities from which they came. They no longer saw themselves as Indian or one of the First Nation communities from which they traced their maternal ancestry, and likewise they did not see themselves as EuroCanadians. Second, there was the development of a leadership that they, as a unified community, could follow (Goulet and Goulet, 2008: 16). Of note was one historical figure, Cuthbert Grant, whose leadership developed a heightened sense of Métis nationalism in the Red River area. Grant was someone whom they could see themselves being represented by, but also a person like themselves who shared specific cultural, linguistic and religious links. And finally they shared a common foe. The 'other' to whom 
they would band against and ultimately take up arms against. While the Hudson's Bay Company represented itself as a commercial interest, their creation and operation in Rupert's Land was more like a dictatorial nation state than possibly any other commercial organization in Canada before or since (Innis, 2001; Ray, 2005; Binnema, Ens and Macleod, 2001). These items conspired together to create the space in which a unique Métis culture and identity could be nurtured and grow.

In looking outside the Red River or Historic Métis Nation territory we can see similar opportunities for a unique identity to be created and fostered into growth. In Labrador, a community evolved from a coming together of the settler community, primarily of British and Irish ancestry, and the Inuit peoples. This new community developed within very specific geographic regions primarily south of Lake Melville away from the Inuit communities (Borlase, 1994; Zimmerly, 1975) found north of Lake Melville along the Labrador coast. There has been a recent move within this community to distance itself from its former Métis roots and see itself as an Inuit community, but as this is still an ongoing issue within the community, its identification here in this research is for the time being still relevant, and an example of how identity can be fluid and change over time in relation to broader political and other contexts.

In Nova Scotia, a community of Métis/Acadians developed as early as the mid-1600s (Surette, 2004: 33). This community suffered equally during the expulsion of Acadians and as a result remained silent about their history until more recent times (RCAP,1996: 257 ; Surette, 2004: 99). 
The Métis in Quebec offers to some, a common basis upon which the Western Métis can trace their origins (RCAP, 1996: 258) especially in the area of Montreal (Stanley, 1975). The community today is geographically centered in the Saguenay region of the province. Very little material has been published on the history of this community. Bouchard's ' $L a$ longue marche du Peuple oublié published in 2006 remains one of the few relevant studies.

The last Métis community that falls outside the Historic Métis Nation is that of the Northwest Territories Métis Nation (NWTMN). As Richard Slobodin notes in his 1966 work on the Métis of the Northwest Territories, until that time little historical work was done on this community $(1966,8)$. While that has changed to some degree over the subsequent decade, primarily as a result of the land claim process in which the NWTMN are involved, there still remains a gap of information in comparison to what is available relating to the peoples of the Historic Métis Nation.

The histories identified above each point to a clue as to the development of a unique Métis identity. As Liu and László state,

Identity from this perspective is not something belonging to the individual, as a set of fixed traits, but something that emerges out of an interaction between the person and the situation. The interplay between a person's self-concept and the situation, containing the social forces emanating from other people and institutions that direct them how to think, feel, and behave is at the heart of the process of identification (Reicher Hopkins, 2001; Oakes, Haslam \& Turner, 1994; Turner et al., 1987)

These interactions occur between a collective and other collectives or the State and have 
historical context which results in the "think, feel, and behave" processes which are part of the communal identity. It is again important to note that Liu and László see this as a communal and not as an individual process.

We can also look at a Métis specific example. Richardson states $(2006,56)$

Métis identity is created through a process of social interaction and dialogic relationships between the inner world and the external world. Relations of unequal power serve as foundational influences negotiated by Métis individuals in the creation of "the sense of Métis self." Métis identity can be examined from a number of cultural and theoretical perspectives. Symbolic interactionist explanations of self-creation posit a dialectical relationship between inner and outer worlds, mediated by one's values and the sorting of experience (Blumer, 1969; Mead, 1934, 1977). Narrative explanations of a storied self resonate with Métis oral traditions and self-creation through storytelling (Bruner, 1987, 1990; Howard, 1991; Polkinghorne, 1988; White, 1997, 2000). Response-based understandings of human behavior offer important insights into the social and interactive processes of Métis identity creation in a climate of social oppression and violence (Wade, 1997). In my studies of Métis history, I found that I agree with the statement: "alongside each history of violence and oppression, there runs a parallel history of prudent, creative, and determined resistance" (Wade, 1997, p. 11 as cited in Richardson).

Richarson's commentary leads to a link with Edward Said's 'Other'. The inner and outer worlds that Richardson identifies, create a notion of 'us' and 'them'. The oral tradition and storytelling of this common history of Métis further strengthens a separateness or difference from the 'other'.

\subsection{Métis Identity and the Royal Commission on Aboriginal Peoples}

The most widely used and recognized definition of Métis identity in Canada is the one developed by the Royal Commission on Aboriginal Peoples in 1996. While it offers a great degree of flexibility, the definition marks an important turning point in recognizing the uniqueness of Métis identity as being more than simply a mixing of two cultural groups, 
but rather a "fully fledged," distinct cultural group.

The purpose of the RCAP was to begin an open dialogue between the nation state and Aboriginal peoples which would also effectively start the road to reconciliation. As part of its mandate, the RCAP recommended definition of Métis people includes any person who,

(a) Identifies himself or herself as Métis and

(b) Is accepted as such by the nation of Métis people with which that person wishes to be associated, on the basis of criteria and procedures determined by that nation be recognized as a member of that nation for purposes of nation-to-nation negotiations and as Métis for that purpose. (RCAP vol4, 1996: 203).

This definition is very significant in that the definition not only recognizes the Métis Nation centered in the prairies of Canada, but also that a number of distinct Métis nations may exist. This point is clearly made evident where the commission notes,

There are many distinctive Métis communities across Canada, and more than one Métis culture as well geographically, the homeland of the Métis Nation embraces the three Prairie Provinces as well as parts of Ontario, the Northwest Territories, British Columbia, and the north central United States. Another Métis people, at least as old as the Métis Nation, is located in Labrador and has maritime traditions. Although the origins of that population are venerable, the application of the term Métis to it is relatively recent. Other Métis communities are found in Quebec, Ontario, Nova Scotia, New Brunswick, British Columbia and the North. Some have significant links to the Western Métis Nation while others do not (RCAP Vol4, 1996: 203).

Métis people living outside of Canada in the northern United States bordering on the Prairie Provinces, however, are not acknowledged by the Government of the United States. 
Almost two decades after the publication of the findings from the Royal Commission on Aboriginal Peoples, of the 10 recommendations made by the commission specific to Métis people and their issues to the federal and provincial governments, little has been done. Implementing these recommendations would be fundamental to any hope of a nation to nation relationship between Canada and the provinces and Métis peoples, but they have been neglected by policy makers and politicians. They have either been ignored or left to the courts for further interpretation. The first three recommendations are of particular importance, and are as follows.

4.5.1 Political negotiation on a nation-to-nation or analogous basis be the primary method of resolving Métis issues.

\subsubsection{Every person who}

(a) identifies himself or herself as Métis, and

(b) is accepted as such by the nation of Métis people with which that person wishes to be associated, on the basis of criteria and procedures determined by that nation, be recognized as a member of that nation for purposes of nation-to-nation negotiations and as Métis for that purpose.

\subsubsection{The government of Canada either}

(a) acknowledge that section 91(24) of the Constitution Act, 1867 applies to Métis people and base its legislation, policies and programs on that recognition; or

(b) collaborate with appropriate provincial governments and with Métis representatives in the formulation and enactment of a constitutional amendment specifying that section 91(24) applies to Métis people. If it is unwilling to take either of these steps, the government of Canada make a constitutional reference to the Supreme Court of Canada, asking that court to decide whether section 91(24) of the Constitution Act, 1867 applies to Métis people. (RCAP Vol4, 1996: 626) 
The first recommendation speaks to the comprehensive claims program which sees Canada, the Province and Territory (where the claim is filed) and the Aboriginal community form a new partnership through a modern day treaty. As separate Métis Nations, each would be able to argue and negotiate settlement with Canada on the specific history of the community and not fall within a pan Métis context. For example we can consider the historic treaty making process of the 1900s in comparison to the Comprehensive Land Claims process today. In the historic Treaty process First Nation (and some Métis) peoples were joined together in arbitrary geographic groups in which the treaty would apply. This meant that communities with little or no cultural or historical relationship to each other would be treated the same in a geographic area that was created by the Canadian government. In the context of the modern claims process, communities come together through common history or culture and negotiate on that basis. This creates a process that is unique and specific to the Nation or nations engaged in the process.

Recommendation 4.5.2 of RCAP, cited above, is at the heart of this thesis. While the federal government and provincial governments in Manitoba, Saskatchewan and Alberta were supposed to have provided funding to Métis organizations to establish membership criteria and membership lists, very little has been done to accomplish this task (AANDC, 2008).

Finally recommendation 4.5.2 as it applies to the recognition of Métis under s91(24) of the Constitution Act, which defines Indians, has been a hot button issue for years and may be soon to be resolved with a decision from the Supreme Court of Canada. To date the lower 
courts have sided with the Métis interpretations of the case law and s91(24) by accepting that the Métis are Indians for the purposes of the law in the CAP-Daniels decision (2013). If this case stands the test of the SCC the federal government will be required to implement the application of "Indian Rights" and obligations on the federal crown coming from those rights to Métis persons as well.

These three recommendations which to date the federal government has failed at implementing will likely be in the spotlight for years to come as a result of the numerous litigations filed by Métis peoples in order to force the issues related to asserted rights and title tied to the failed implementation of the RCAP recommendations. The struggles over land, resource and other rights and resistance to recognize these rights underlines how relevant Métis identity issues continue to be today.

\subsection{Métis Organization Definitions}

Much could be written drawing on linguistic philosophy about gaining a better understanding of the language used in identifying Métis, to come to some formal definition of Métis identity. For example an approach that sees Métis as both a separate Nation and a more pan Aboriginal group would meet the political aspirations of the Métis national organizations and not deny Aboriginal rights to those people who do not fall within the definition of a Historic Métis Nation.

Additionally, the etymology of the term Métis could be looked at critically but this would move this research beyond its original intent. The histories behind the use of terms such as 
mestizo, half breed, mulatto or bois brule that have evolved along with the term Métis through their usage as a tool of colonial power, racist policies or control of a certain class of population, are important (Peterson and Brown, 1985; Slobodin, 1966) but are not reviewed here. For the purposes of understanding who the Métis are, Slobodin provides a concise discussion on the link between the more universal term Métis and the use of the term Métis in the Canadian context (Slobodin, 1966). He notes,

To describe the subjects of this study as persons of mixed racial and cultural background is anomalous from a scientific point of view. It is a truism in anthropology that all human populations are "mixed" in heredity - or, more properly, that they are genetically heterogeneous - and that all cultures have more or less diverse origins. $(1966,1)$

And further,

In short, the Métis are distinctly not the hybrids of two or more homogeneous races each with a monolithic cultural tradition. $(1966,1)$

It is this unique culture within Canada and northern United States which emerged to be more than a mere mixed racial and cultural background but which developed into a distinct group of cultures, with which this research deals.

While there are different interpretations as to what it means, the term Métis has gained widespread acceptance. In terms of the organizations that represent Métis populations, there are two important stances on what it means to be Métis. The first comes from the Métis National Council (MNC). This political organization has its roots within the historic Métis Nation or Red River Métis, the community of Métis that can trace their genesis to the area surrounding what is now the city of Winnipeg, Manitoba, and has been a leading organization on Métis rights cases in Canada west of Ontario. The MNC define Métis as, 
Métis means a person who self-identifies as Métis, is of historic Métis Nation ancestry, is distinct from other Aboriginal Peoples and is accepted by the Métis Nation (MNC, 2010).

Related definitions provide further insights to better understand the MNC position,

"Historic Métis Nation" means the Aboriginal people then known as Métis or HalfBreeds who resided in Historic Métis Nation Homeland;

and,

"Historic Métis Nation Homeland" means the area of land in west central North America used and occupied as the traditional territory of the Métis or Half-Breeds as they were then known; (MNC, 2010)

Add to this the definition by the MNC of how they see the historic Métis Nation and one can clearly see that the MNC views the Métis as tied to a specific geography in Western Canada and parts of the bordering United States, and that this place is tied to their identity as a people. In providing more analysis to the definition it can be broken down into four separate steps. The first is self-identity. The individual must clearly feel they are Métis and that this identity defines somewhat who they are. This would not include an individual who has Métis ancestry but does not associate with being Métis. The second, as mentioned, is the tie to the historic Métis Nation. For the MNC, this requires a connection to a specific geographic area, with roots in and continued connection to the Red River region. The third part of the definition is the distinctiveness of being Métis in relation to "other Aboriginal Peoples". This seems to be aimed at distinguishing Métis people from their First Nation heritage. Finally, and perhaps most contentious, is the requirement to be accepted by the Métis Nation. It is not entirely clear if the MNC is referring here to being accepted by the larger community, or if they are referring to the political body that represents the Métis Nation as the ultimate authority in deciding who belongs and who does not. This latter 
option is cause for concern as it leads to the ability of an elite within the organization determining who is and who is not a part of the community. However, at the moment it appears that there is no formal test for this criterion. The MNC definition clearly excludes other groups elsewhere in Canada who identify themselves as Métis.

A second definition comes from the Congress of Aboriginal Peoples (CAP), based in Ottawa. CAP, like the MNC, is a political organization, but unlike the MNC, CAP operates across Canada in representing Métis, non-status Indians and First Nations people registered under the Indian Act but without band membership. CAPs organizational makeup includes provincial affiliate organizations which represent the aspirations of the Aboriginal peoples who are members (CAP, 2014). In turn, these provincial groups use the offices of CAP to provide national level support especially in dealing with issues that cross provincial jurisdictions. In its definition of Métis, CAP states,

'Métis people are located in all of the provinces and territories of Canada. These persons, who may or may not be entitled to status under the Indian Act, are Métis culturally, historically, and for purposes of constitutional recognition. Some of this group are a distinctive mixed blood population, others are closely identified with the history and culture of the French/Cree Métis in southern Manitoba and central Saskatchewan in the 1860s.' (CAP, 2010)

The CAP definition is clearly much more inclusive and does not require recognition from the "Métis Nation" or any formal political or administrative body. However, the CAP could also exclude a segment of the population which may identify as Métis. Selfidentification is not highlighted in this statement as it is in the MNC definition. For the CAP definition, a person of mixed ancestry (e.g., European and First Nation), would more than likely be considered as being Métis even though they themselves may feel that the 
way they were raised, the cultural traits in which they lived their daily lives, and therefore their identity, is non Aboriginal or is tied to the specific First Nation history that part of their ancestry derives from.

The Manitoba Métis Federation that falls within the MNC umbrella, who claim Manitoba as the birthplace of the Métis Nation state,

The Métis are a people of North American Indian and European ancestry who coalesced into a distinct nation in the northwest in the late 18th century. (MMF, 2010)

This identity, as defined by the MMF, restricts one's being Métis to a specific geography and history, thus only a person from the Canadian prairies need apply. This would leave all others with no historic or contemporary tie to the northwest outside the definition. As well, those whose Métis identity is associated with Inuit ancestry are outside the scope that the MMF would find acceptable. This clearly shows the contested and complex nature of identity and more specifically how power plays a role in determinations that serves the best interest of one group over others. It should be noted that the definition offered by the MMF seems at odds with that of the MNC under whose umbrella the MMF falls. This difference should be seen in the same light as differences that might occur between the federal and provincial governments or differences of opinion that can be found between First Nation bands and tribal councils and the Assembly of First Nations. It is not the purpose of this research to explain why different organizations would have different definitions but to recognize the complexity of the issue of Métis identity and how it is defined by various organizations. 


\subsection{Concluding Thoughts}

This chapter has identified the contested nature of identity and the difficulty that occurs within any attempt to define Métis. Whether seen as a nation, as would be the direction sought through the national Métis organizations such as the MNC or MMF, or as a form of personal identity as suggested by the Royal Commission on Aboriginal Peoples, there is general recognition that Métis are a result of the coming together of two distinct cultures, which created a distinct peoples with unique histories, culture and heritage.

As has also been shown in this chapter, there are significant problems in the use of the term Métis. It relates to both a nation that is a group of people with a shared history, geography and in some cases language, who are united politically by their identity, as well as a term that refers to a loosely identifiable national population where there may be distinct "sub groups" with similar histories.

It should also be noted that not only do we have to take into account the imposition of identities by central governments on subjected peoples; we must also recognize that where an identity has been constructed, others who may not feel that their identity has been captured for political reasons may appropriate the constructed identity. This is the case in Labrador where the once identified Labrador Métis Nation has revamped its identity to where it no longer sees itself as Métis but as an Inuit community. 


\section{Chapter: Métis Case Law: Arguing Identity}

\subsection{Introduction}

The courts, as a tool of government and a means by which power and control may be asserted, have significant influence in determining who is Métis and who is not Métis. Unfortunately, as I explain below, key court decisions have not been effective in identifying a reasonable set of tools to assist in arriving at a satisfactory mechanism to determine Métis identity. The following section provides a synopsis of four court decisions relevant to this research which are important because the concept of Métis identity has been contested through the Canadian courts.

The first and most significant of the cases in respect to this research, is R. v. Powley, [2003] 2 S.C.R. 207, 2003 SCC 43 (R. v. Powley) that established the notion that contemporary Métis identity is linked to communities. This requirement of a link to a historical community was an adaptation of the earlier 1996 Supreme Court of Canada decision in R. v. Van der Peet, [1996] 2 S.C.R. 507. In the Van der Peet case, the Supreme Court of Canada established a test that would assist in the determination of whether an Aboriginal (in this case First Nation) right existed.

Three subsequent cases used the Powley decision as a basis by which the court rendered its decision. The first of these is The Labrador Métis Nation v. Her Majesty in Right of Newfoundland and Labrador, 2006NLTD119 (LMN v. NFLD) which was argued before the Supreme Court of Newfoundland and Labrador, Trial Division and subsequently appealed at the Supreme Court of Newfoundland and Labrador, Court of Appeal. The 
second case is an appeal heard before the Supreme Court of British Columbia, R. v. Willison, 2006 BCSC 985 (R. v. Willison) which offers significant opportunities on expanding the argument about that 'place'. Specifically it highlighted the relationship between the historic and contemporary Métis community and thus offers significant connections between geography, identity and law. The third case, Her Majesty the Queen v. William Neal Goodon (R. v. Goodon) was heard before the Provincial Court of Manitoba. This case, while arguably less influential given that it was in a lower court, remains significant because of the expanded understanding of traditional territory that it offered, providing a more accurate reflection of how Métis communities relate both historically and contemporarily with Métis traditional activities.

While there are other relevant cases which could have been identified in this research, the cases outlined above provide a legal basis by which the concept of identity and place are equally important in the decisions made by the court. In addition these cases provide a foundation of proof that clearly suggests the importance of geographical principles and thought within Canadian Aboriginal law.

\subsection{Powley}

Following a successful moose hunt on October 22, 1993, two Métis men, Steve and Roddy Powley, a father and son, returned to their home in Sault Ste. Marie, Ontario with a bull moose in the box of their truck, in plain view. Shortly after their arrival home, two Ministry of Natural Resources Conservation officers from the Province of Ontario presented themselves at the Powley residence. The officers, in their court testimony, noted that 
neither Powley had a valid Province of Ontario moose hunting license. Further, the moose had a hand written note attached to its ear, in a manner similar to how a provincial hunting tag would be placed on a harvested animal, which stated the following information "the date, time and location the moose was killed at...", as well as Steve Powley's Métis card number. The note also contained a remark that the Powleys were "harvesting my meat for the winter" (Ontario Court 1998: para11). A week later the Powleys were formally charged under the Province of Ontario's Game and Fish Act for illegal possession of the moose.

The case was first heard by Provincial Court Justice Vaillancourt during the spring and summer of 1998 in the Ontario Court of Justice, Provincial Division.

On the issue of defining Métis, Justice Vaillancourt clearly recognized it as a difficult, but important task (Ontario Court 1988: para 37). After articulating the issue he placed the burden of a definition for the Métis in the hands of both parties to come to a fair and equitable definition outside of the court process. On this issue he wrote,

I am of the view that a court is not the ideal forum to deal with political matters. The definition question would best be addressed through negotiation and consensus building rather than an adversarial process (Ontario Court 1998: para 43)

That said, Justice Vaillancourt recognized the importance of the question and attempts to offer a definition,

Without a universally accepted definition of Métis to be found, I shall attempt to distil a basic, workable definition of who is a Métis. Accordingly, I find that a Métis is a person of Aboriginal ancestry; who self identifies as a Métis; and who is accepted by the Métis community as a Métis. (Ontario Court 1998: para 50) 
One issue that Justice Vaillancourt raises is the "generic" term Métis. He writes,

The generic term Métis forces individuals to not only self-identify but they must also piece together the existence of a definable Métis existence from location to location (Ontario Court 1998)

We should consider that Justice Vaillancourt is raising the notion that the term Métis not only applies possibly to a specific people, i.e. the people of the Red River, but also that it has the capacity to refer to numerous peoples who may have certain shared traits but where a key component to their identity as a people may also be unique from the larger population. Justice Vaillancourt may be moving towards the recognition that place based identity should be a factor in how the term Métis is defined.

For the remainder of the decision, Justice Vaillancourt speaks to the existence of a historic Métis community around Sault Ste. Marie. He characterizes the rights of Métis as a right protected by Section 35 of the Constitution Act 1982. In concluding his analysis of the case, Justice Vaillancourt ruled in favor of the Powleys. This question of community provided a significant and possibly the most important and philosophically challenging question that is raised in this decision and which played a role in the Powley case as it progressed through the Canadian judicial process. In successive court decisions relating to the Métis what is meant by the term community, and as it relates to Métis, more appropriately, communities? Courts, government agencies, and political organizations representing the various Métis peoples have all incorporated acceptance of the individual by a collective as an important criterion for being considered Métis. The requirement that a Métis person belongs to a broader community as part of their identity, and an understanding of what this means, is a key element of this research and it plays a valuable 
role as the basis by which one is able to assert a Métis identity.

Much work has been undertaken by sociologists and others in not only providing a definition of what community is in a more qualitative way (Gusfield, 1975; McMillan and Chavis, 1986). McMillan and Chavis (1986) define a sense of community as "a feeling that members have of belonging, a feeling that members matter to one another and to the group, and a shared faith that members' needs will be met through their commitment to be together" (1986:9). This can be seen in the context of Métis communities throughout the 2013 Senate Report “The People Who Own Themselves”: Recognition of Métis Identity in Canada (Senate of Canada, 2013)

A similar definition of community is a "unified body of individuals" (Merriam-Webster online) or "a body of people having a religion, a profession, etc., in common" (Canadian Oxford Dictionary, 2004; 310). More substantial insight into the definition of community is made by White and Maxim who define community in a manner that aligns nicely with trying to understand Métis identity. They state,

Communities are social constructions built through the interaction of human actors with each other and with their environment. As such, a community is both a physical entity and a relationship. Organizations, institutions, structures of custom, and patterns of everyday life are products of our interrelationships in our communities. (White and Maxim, 2003:7)

Peter Block states that "Community is fundamentally an interdependent human system given form by the conversation it holds with itself (Block, 2009: 30). A second path to looking at community for Métis people is centered on place. As Deloria (1994: 63) puts it, "American Indians hold their land-places as having the highest possible meaning, and all 
their statements are made with this reference point in mind."

Examples of places with significant meaning to Métis are Batoche, Saskatchewan which was the site of the battle between the Métis and British/Canadian army in 1885 and which is now a National Historic Site managed by Parks Canada. Larger scale sites would include the Province of Manitoba, whose creation can be directly attributed to the Métis Provisional Government as part of the Red River Rebellion (Parks Canada, 2014). However beyond these few examples Métis places have been erased from public thinking. It is within the Western or Euro Canadian thinking that the courts generally rely on making their determinations, leaving Aboriginal peoples, or more specifically Métis for the purposes of this paper, searching if not grasping for similarities between their concepts of place and community and those expected by the courts.

In January 2000, the Ontario Supreme Court of Justice confirmed the lower court decision in R. v. Powley. This in turn was again appealed by the Crown to the Court of Appeal for Ontario demonstrating the strong resistance of the provincial government to recognize Métis resource rights. While their underlying motivations are not clear, it is likely that there were concerns tied to the legislative responsibility provinces have for Métis people. In February 2001, the Court of Appeal in a unanimous decision upheld the decision by the Ontario Supreme Court of Justice which recognized that the Powleys had a Métis Aboriginal right to hunt for food as protected in Section 35 of the Constitution Act 1982. 
The judgments in these lower court Powley decisions were broad in scope and significant for paving the way to the Supreme Court of Canada decision. However, overall there was limited capacity to engage in an in-depth legal argument about Métis identity. To be fair, the courts are limited to rendering a decision based on the evidence provided. It is the lawyers for the parties that dictate what may be heard based on the witnesses they bring to the court to strengthen their position. That said, too often the courts are forced to interpret material which is either irrelevant to the situation or that is biased to benefit one party, for example census data that could be used to highlight population levels justifying a pro or con argument, but which are based on individuals self-identifying on a questionnaire. This limits the court's ability to fully respond to social and cultural issues in situations where there is no right or wrong, guilty or innocent decision to be made.

The provincial rulings led to the case being sent to the Supreme Court of Canada. While lower court rulings assist policy makers and legislators in formulating policy and legislation, primarily at the provincial or territorial level, it is at the Supreme Court of Canada where judicial rulings have the greatest impact on national level policy development.

The Supreme Court of Canada released its judgment in R. v. Powley on September 19, 2003. In a unanimous decision, the court found that there was a contemporary Métis community with historic links in the area of Sault Ste. Marie and that this community had an Aboriginal right in the harvesting for food for subsistence (but not for commercial purposes) as affirmed in section 35(1) of the Constitution Act 1982. In an analysis of the 
Supreme Court ruling, noted legal scholar Thomas Isaac writes,

In Powley, the court held that the proper characterization of the claimed Métis right was a right to hunt for food near Sault Ste. Marie, not a right to hunt moose for food. The court upheld the lower court decisions respecting the distinctive Métis community of Sault Ste. Marie and that such a community existed, even if not always formally designated as such. (Isaac, 2004: 285)

What is of particular interest is the way the question of community was framed. In trying to answer the question "Who is Métis?", the courts, placed a high degree of importance on the notion of membership with a larger group or nation connected to a specific location, which is seen in the use of the term "contemporary or historic community". In looking at the decision by the Supreme Court of Canada in R. v. Powley, the court writes,

Aboriginal rights are communal, grounded in the existence of a historic and present community, and exercisable by virtue of an individual's ancestrally based membership in the present community. (SCC, 2003)

Further to this at paragraph 12 of the decision the court, on defining what is meant by a Métis community, pronounced that,

A Métis community can be defined as a group of Métis with a distinctive collective identity, living together in the same geographic area and sharing a common way of life. (SCC 2003: para 12)

The court continues,

It is not necessary for us to decide, and we did not receive submissions on, whether this community is also a Métis "people", or whether it forms part of a larger Métis people that extends over a wider area such as the Upper Great Lakes. (SCC 2003: para 12)

In its ruling, the Supreme Court of Canada is grappling with the notion of place and how place and identity are interconnected for Aboriginal peoples. The problem is that the court seemingly steered away from dealing with this issue head on and instead, framed the issue 
within the narrow approach of legal jurisprudence. If the court had been truly interested in providing a thorough response to the issue of Métis identity in Canada, it would have considered whether distinct Aboriginal peoples have different perceptions of place and how their philosophical notions of what they, in this case Métis people of the Sault Ste. Marie area, view as their community, homeland or traditional territory. Thus I would argue the fundamental debate that the courts must be prepared to enter into is whether Western or Euro Canadian (settler society) perceptions of place trump those of the Indigenous peoples of Canada.

The most significant part of the R. v. Powley decision lies in what has been characterized as the Supreme Court of Canada's 10 part test. This test is made up by a series of questions which assist in the determination of the "entitlements of the Métis under section 35 of the Constitution Act, 1982" (SCC 2003; para 18). The Supreme Court of Canada modified an existing test which had been part of the 1996 Supreme Court decision in R. v. Van der Peet. The modification centered on the historical genesis of Métis peoples, following contact between European and First Nation and Inuit peoples. The court writes,

We accept Van der Peet as the template for this discussion. However, we modify the pre-contact focus of the Van der Peet test when the claimants are Métis to account for the important differences between Indian and Métis claims. Section 35 requires that we recognize and protect those customs and traditions that were historically important features of Métis communities prior to the time of effective European control, and that persist in the present day. This modification is required to account for the unique post-contact emergence of Métis communities, and the post-contact foundation of their Aboriginal rights. (SCC 2003: para 18)

While Van der Peet, a First Nations rights case, held that the historical relationship between a community and land rights must occur prior to the arrival of Europeans in a given area, 
R. v. Powley held that it was at the time of effective control, that is when there is clear control by the nation state over an area, where a historical community must be in place in a given area which practiced a given activity. The notion of effective control has been at times difficult for the courts to establish. Teillet and Madden, in highlighting the concept of effective control in the R. v. Goodon case, note that the trial judge in Goodon offered that as the growth of the Red River Settlement occurred in stages over many years, the point at which a specific place is under effective control may vary (Madden \& Taillet, 2009). At the same time a December 2010 decision by the Alberta court, R. v. Hirkeshorn, identified the arrival of the North West Mounted Police, the forerunner of the RCMP, as the organization which established effective control. One thing is clear with the notion of effective control. The varying circumstances under which this concept is defined leads to uncertainty and differences of opinion, which is exacerbated by the fact that the historical record is incomplete. In this situation then it should be recognized that no amount of research can provide a definitive answer to certain legal aspects of Métis identity. Given the ambiguities and contested nature of identity, the same can be said of identifying contemporary community using statistical data. As I argue below, the problematic nature of satisfying parameters in meeting the Powley test is rooted in a colonialist mentality within the dominant non-Aboriginal settler society. 
The most significant part of the Powley decision lies in two points of the 10 part test as articulated by the Supreme Court of Canada. The first four parts of the test are closely related to defining Métis identity:

1) Characterization of the Right; what activity is being claimed by the Aboriginal group as a right. In the case of R. v. Powley it was the rights to harvest moose.

2) Identification of the historic rights-bearing community; this point is linked to geography and history. The court is requiring that at some point in the past there was an identifiable community in the same general area as where the undertaking of the Aboriginal right occurred and that the individual(s) involved in undertaking the activity link their ancestral heritage to this historic community.

3) Identification of the contemporary rights-bearing community. Key to this is the requirement that any claimant must be able to identify themselves as part of a current day (contemporary) rights bearing community. This is really two issues folded together into one. The first deals with the contemporary nature of a community and the second is that the community must also be rights bearing.

4)Verification of the claimants' membership in the relevant contemporary community; the Supreme Court of Canada recognized that determining membership in the case of the Métis would not be as simple as it is for determining First Nations membership in a First Nations community (para 29). The court did note that membership and identity are intricately tied to each other and that any comprehensive definition of who a Métis is would also require some form of membership test (SCC, 2003: para 30). 
R. v. Powley test items 5 through 10 are of less significance in the current research than the first four items so are not expanded on. They are as follows:

5) Identification of the relevant time frame.

6) Determination of whether the practice is integral to the claimant's distinctive culture

7) Establishment of continuity between the historic practice and the contemporary rights asserted

8) Determination of whether or not the right was extinguished

9) If there is a right, determination of whether there is an infringement

10) Determination of whether the infringement is justified (SCC, 2003: para 30)

Before continuing with looking further into the question of Métis identity and community as raised by the R. v. Powley decision it would be appropriate to first briefly highlight three further court cases involving Métis peoples and how the substantive issues of identity and community were dealt with by these court cases.

\subsection{Labrador Métis Nation}

The first, in order of date of decision, is a case involving the Labrador Métis Nation (LMN) and the Government of Newfoundland and Labrador. Culturally this community finds its ethno genesis in the interaction between the Inuit of Labrador and the early Basque and British traders (RCAP, 1996: 256). At the time of the court case, the federal government had been providing funding to the LMN to assist with a strength of claim study. This 
strength of claim would provide the basis for the LMN entering into formal negotiations with Canada.

The case, The Labrador Métis Nation v. Her Majesty in Right of Newfoundland and Labrador, 2006 NLTD 119 (CanLII), was heard before the Supreme Court of Newfoundland and Labrador, Trial Division, with the judgment rendered by the court in July 2006. The case emerged out of a conflict surrounding further construction of the transLabrador highway, a $250 \mathrm{~km}$ section between Happy Valley Goose Bay and the community of Cartwright in Labrador. The Labrador Métis Nation argued that as an Aboriginal people, the Province of Newfoundland and Labrador had neglected its duty to consult them on a matter which might impact their asserted or recognized rights as identified in common law, based on the 2004 Haida decision ${ }^{1}$ and based on requirements as set out in R. v. Powley. The latter provides the guidance to the courts in the eventual establishment of the Labrador Métis Nation as a Métis people who are Aboriginal peoples within a rights bearing Aboriginal community as defined by section 35(2) of the Constitution Act 1982.

In his judgment, Justice Fowler used the 10 part test as established in R. v. Powley as the primary legal argument for his decision, including the criteria of Métis identity and the need to identify a contemporary community. His decision that the Labrador Métis Nation were an Aboriginal people of Canada drew explicitly from the R. v. Powley precedent and the Royal Commission on Aboriginal Peoples, recognizes the Labrador Métis as a legitimate Métis peoples He writes,

\footnotetext{
${ }^{1}$ Haida Nation v. British Columbia (Minister of Forests), 2004 S.C.C. 73 (S.C.C.)
} 
[8] In the Powley case (supra) the Supreme Court of Canada at paragraph 10 in relation to the term "Métis", and relying on the reference in the 1996 Canadian Government Royal Commission on Aboriginal Peoples: [Report of the Royal Commission on Aboriginal Peoples (Ottawa, 1996)]; the Royal Commission, stated,

"The term "Métis" in s. 35 does not encompass all individuals with mixed Indian and European heritage; rather, it refers to distinctive peoples who, in addition to their mixed ancestry, developed their own customs, way of life, and recognizable group identity separate from their Indian or Inuit and European forebears. Métis communities evolved and flourished prior to the entrenchment of European control, when the influence of European settlers and political institutions became pre-eminent."

[9] And further that,

"The French referred to the fur trade as coureurs de bois (forest runners) and bois brules (burnt-wood people) in recognition of their wilderness occupations and their dark complexions. The Labrador Métis (whose culture had early roots) were originally called "livyers" or "settlers", those who remained in the fishing settlements year-round rather than returning periodically to Europe or Newfoundland. The Cree people expressed the Métis character in term Otepayemsuak, meaning the "independent ones". [Report of the Royal Commission on Aboriginal Peoples, vol. 4 (Ottawa: the Commission, 1996), at pp. 199-200 (“RCAP Report").]

(NLTD, 2006; para 8 \& para 9)

Justice Fowler writes in his decision,

What is significant by reference to the Labrador Métis is the definitive language used by the Supreme Court of Canada. It, no doubt gave great deference to the Royal Commission in relying on its references as to who identified as Métis people. The Supreme Court of Canada, if it felt uncertain; could have, but did not, use any conditional terms in its reference to Métis people in Labrador. It began by expressly using the grammatical definite article "the" to begin its reference to "The Labrador Métis." (NLTD, 2006; para 10)

The case, then, reaffirmed the existence of a historic and contemporary Métis community in Labrador who are known as the Labrador Métis. He further endorsed the Royal Commission Report was a document of high quality and value by stating, 'This was 
certainly not an unsophisticated document generated by unlettered individuals' (NLTD, 2006: para14).

The second substantive issue of this research which was dealt with by Justice Fowler in his decision relates to the 'Identification of the contemporary rights-bearing community' (NLTD, 2006; para 55 to para 73). What is in my opinion, of relevance here is that Justice Fowler has changed the scope, ever so slightly, of the term community as it is interpreted in R. v. Powley. In Powley, as I have noted earlier in this paper, the lower court decisions and the Supreme Court were clear in identifying Sault Ste. Marie and environs as being the area of the contemporary Métis community in that case. That is, it seems to me, the courts in R. v. Powley successfully bounded an area with a tight spatial framework, or more appropriately a tight legally defined place, as being where Métis are located today. In the Labrador decision, Justice Fowler expands this notion of community and place by writing,

From the above I am satisfied that there is a strong case to be made for recognizing a regional community of Labrador Métis people of mixed Inuit and European ancestry along the east and south coast of Labrador.(NLTD, 2006; para72)

My argument here is that this discussion of a 'regional community' by Justice Fowler is a different notion of place than that which was used by the Supreme Court of Canada in R. v. Powley. It further is a more appropriate recognition of how Métis peoples have adapted how they live in place from that which was used by their First Nation or Inuit cultural histories. The 'regional community' in this case may be seen to be more in line with what we would refer to as a traditional territory. Instead of the narrow place centered definition offered in R. v. Powley, we now have a 'place expanded' definition. 
This sense of place is central to the Labrador Métis as it not only identifies their traditional territory, but it is this same sense of place that separates them from the Labrador Inuit of Nunatsiavut who live along the Labrador Coast North of Lake Melville. In testimony before the RCAP Bernard Heard of the Labrador Métis Nation stated,

For many generations...before Newfoundland and Labrador joined with Canada, and even long before Canada itself existed as a nation, the Labrador Métis, who were then commonly referred to as the 'livyers', or 'settlers', lived on the coast, both north and south, in complete harmony with the land and the sea, much the same as their Inuit and Indian neighbors. The same can be said for those who ultimately settled in the Lake Melville region and became the celebrated trappers of central Labrador....

[T] he people in such places as Paradise River, Black Tickle and Pinsent's Arm on the south coast [who are now calling themselves Métis] are essentially no different than the Inuit of Rigolet, Postville, or Makkovik on the north coast. [I]t is only geography and the attitude of outsiders that separates them....

I say to you and to Canada we are not livyers. We are not settlers. We are Métis the progeny of our Indian and/or our Inuit and European settlers who long ago settled this harsh and beautiful land when others considered Labrador to be the land God gave to Cain. (RCAP, 1996: 256)

In concluding the discussion of this case I again point out its importance in two areas. The first is in clearly accepting the existence of the Labrador Métis as an Aboriginal people as defined in the Constitution Act 1982. Secondly, the decision allows for the "community" requirement to be satisfied by a historical connection to a broad region, as opposed to a specific town or village. This is more appropriate, as it is more closely related to an Aboriginal understanding of place.

It should be noted that this case in which the Labrador Métis Nation was successful in its arguments before the Supreme Court of Newfoundland and Labrador, was an Aboriginal community as defined in s.35 of the Constitution Act 1982. As such, governments had a 
duty to consult on projects within the traditional territory which could impact known or asserted Aboriginal rights. The decision was appealed by the provincial crown to the Supreme Court of Newfoundland and Labrador Court of Appeal where the Labrador Métis Nation was again successful. In May 2008 Government of Newfoundland and Labrador applied for an appeal to the Supreme Court of Canada which was subsequently refused.

\subsection{Willison}

Another important court case influencing understandings of Métis identity and rights is R. v. Willison, 2006 BCSC 985. More than any Métis rights case that preceded it, or any since, this case has been especially relevant to the issue of identifying a contemporary Métis community that is in turn linked to a historic Métis community.

The facts of the case are as follows. In late Fall 2000, Mr. Gregory Willison admitted to officials that a deer he was in possession of was shot by him. The animal he shot, a mule deer, was in season but there were specific characteristics which the animal must possess for it to have been harvested in accordance with regulations, namely the number of points on the antler. Mr. Willison's deer did not meet this physical requirement. At the time he shot the deer, Mr. Willison claimed an Aboriginal right to harvest as he was a Métis with an ancestral tie to the Okanagan area of British Columbia where the hunt had taken place. Mr. Willison was charged by the BC Conservation Officer with a number of hunting related offences including not being in procession of a valid hunting license. The case was first heard before the British Columbia Provincial Court and in May 2005 Mr. Willison was found by the court to have an Aboriginal right to hunt for food as set out in the Powley 
case. As could be expected in an Aboriginal rights based case, the crown appealed the acquittal.

In the crown appeal to the British Columbia Superior Court, the crown argued that the trial judge erred on four aspects as found in the Powley test which were as follows:

1) In finding an historic rights bearing Métis community in the Falkland area;

2) In finding a contemporary Métis community;

3) In finding a continuity between the historic practice and the contemporary right asserted; and,

4) In finding the respondent was a member of the alleged contemporary Métis community. (BCSC, 2006: para 6)

The case and decisions at both the trial court level and Superior Court clearly point to the importance of place in the question of Métis rights. The crown, the defendant, and the judge all accepted the need to belong to a Métis community in order to have Métis rights, indicating that this had become firmly entrenched in Canadian society. The Crown, in its argument, felt that a community should be defined as a group of individuals with no communal ties other than that they lived in the same area and identified themselves as a contemporary Métis community (BCSC, 2006; para21 and para 22). Jean Teillet, legal counsel for Mr. Willison, articulated the court's findings on this matter by noting,

The trial judge held that the existence of a contemporary rights-bearing community does not hinge on precise numbers of persons, but rather on the conclusion that a meaningful number of persons are Métis and work together to preserve their community. (Teillet, 2006: p42) 
On the boundaries of a legitimate community, the British Columbia Superior Court had concerns, articulated by Justice Williamson in his decision as follows,

A reading of Powley discloses that a "community"... should demonstrate a people with a distinctive collective identity, sharing a common way of life, and living together in the same geographic area. (BCSC, 2006: para 46)

He continues,

I agree with the Crown that in effect the learned trial judge expanded the definition of community found in Powley to include a geographically wide, loosely affiliated group of people of mixed ancestry rather than a group with a distinctive, collective identity, living together in the same geographic area and sharing a common way of life. (BCSC, 2006: para 48)

It should be noted that the trial judge felt that the definition of community in the context of the case was of importance. However, the trial judge opened up the notion of community to the point that it could not be bounded as a spatial construct (i.e., a town or legally defined place) but instead was a social construct which he called a 'cultural community' (BCPC, 2005: para 81). It was this notion of the cultural community that was refuted by the Superior Court Justice highlighted above.

What this case leads to is how one defines a community when it is recognized as a social construct. Can it be quantitatively assessed?. This issue clearly demonstrates the need for a methodology in which some level of proof of a bounded area that has a physical sense which can be identified through a quantitative process. As long as courts place a higher burden of proof on Aboriginal peoples to justify their Aboriginal rights in a manner convenient for contemporary settler society to understand, Aboriginal peoples will be forced to adopt systems that translate their traditional knowledge, oral histories and values 
into a form that is understandable As in this case where the cultural community $\mathrm{Mr}$. Willison belonged to was not bounded by some geographical extent thus its existence was seen as not meeting the requirements of the Powley test, as noted above. We must consider the implications of considering the court's view or interpretation of community as identified in this case. Is it indeed incorrect to consider a cultural community without a distinctive tie to place? I would suggest that the foundation of an Aboriginal person or community's assertions of rights must be linked to a physical connection to place. This connection is what we would generally view as a traditional territory. If this were not the case Aboriginal people who move from one coast to the other, could claim the whole area as being part of an Aboriginal community writ large, with no connection to the specific place they occupy.

The difficulty though lies in how Aboriginal peoples interact with the state and the courts in having their concepts of place and traditional territory be respected. Dale Turner states, ...Indigenous peoples cannot allow dominant culture to dictate their legal and political realities. Greater participation in the state's legal and political practices is vital to our survival as Indigenous peoples, but at this time in history it is by no means clear how we ought to participate. $(2006,11)$

Using state accepted tools and methodologies consistent with Western scientific practices as a means of telling the Métis stories which in turn protect their historical rights will be central to the analysis of the 2006 census data which I will undertake in a subsequent chapter as well as its application in the section on case studies. 


\subsection{Goodon}

The final case of relevance to this research, which provides a slightly different option in the determination of a contemporary Métis community, is found in the Provincial Court of Manitoba decision in R. v. Goodon, 2008 MBPC 59. In the Goodon case, as in Powley and Willison, the case centered around the issue as to whether a particular Métis group had an Aboriginal right to harvest, in this case the hunting of ducks in the area of Turtle Mountain, Manitoba.

In his judgment, Justice Combs identifies a number of communities by naming them (MBPC, 2008: para53) yet he offers that the particular Métis community relevant to this case occupies not just a specific town or village but a much larger area that essentially can be identified as South Western Manitoba. This decision offers a variation on the Willison decision of determining Métis communities and follows the concept of traditional territories.

Of note on this last point, it would be a Supreme Court of Canada decision in 2014 before First Nation peoples would be offered the same level of acceptance of their concept of territory. (Tsilhqot'in Nation $v$. British Columbia, 2014 SCC 44). While this case is in its early stages of having implementation impacts both for First Nations and for the state, and while this case focused on First Nation title (land ownership) and may not be immediately applicable to Métis title rights, it is clear the the Tsilhqot'in decision could play a future role for Métis. Importantly, the ruling allows for the migratory or nomadic nature of Tsilhqot'in peoples' movement across their traditional territory to not be held against them 
when it came to proving title. As the Supreme Court identified,

While the population was small, he [i.e., the judge] found evidence that the parts of the land to which he found title were regularly used by the Tsilhqot'in, which supports the conclusion of sufficient occupation. The geographic proximity between sites for which evidence of recent occupation was tendered and those for which direct evidence of historic occupation existed also supports an inference of continuous occupation. And from the evidence that prior to the assertion of sovereignty the Tsilhqot'in repelled other people from their land and demanded permission from outsiders who wished to pass over it, he concluded that the Tsilhqot'in treated the land as exclusively theirs. The Province's criticisms of the trial judge's findings on the facts are primarily rooted in the erroneous thesis that only specific, intensively occupied areas can support Aboriginal title. (Tsilhqot'in Nation v. British Columbia, 2014 SCC 44)

This decision clearly offers two important opportunities that this research attempts to highlight either directly or indirectly. The first relates to how different Métis communities used their traditional territories, and offers those with a nomadic structure some hope through the opportunities this decision may offer them. Secondy, the court recognized the substance of, in this case, a First Nation people's form of living as being geographic in scope. This could ultimately offer Aboriginal peoples a tie between traditional teachings and western science.

\subsection{Conclusion}

In conclusion, this section shows the importance that the courts have placed on defining contemporary Métis communities. It also provides a clear history of how the nation state has reneged on its obligations to Métis peoples by deferring meaningful dialogue with them to come to a common acceptable understanding as highlighted in the Royal Commission on Aboriginal Peoples. 
It should also be noted that while Métis cases identified above have heard Métis voice throughout the court process (Ray, 2011), what they hear and how they act upon that information are two separate issues. As Ray states,

In my opinion, there are three reasons why judges tend to value historical experts roughly equally. The first is the common underlying notion that anyone can be an historian. The second is the lingering notion that documents are mostly "plain on their face." The third is the belief that historians are essentially clerks, whose primary role is to bring to the court's attention those documents that historians deem to be relevant. (Ray, 2011: 158)

In addition he states,

Succeeding generations of academics have deployed different theoretical and methodological frameworks, thereby continually altering our understandings of Native history. In this way, scholarship has helped to keep the Aboriginal past alive in the academy and connected to its present interests.

Courts, on the other hand, use history to bury the past rather than to continually revisit it. (Ray, 2011, 152)

What Arthur Ray, a respected historical Geographer is pointing out, in a more nuanced fashion, is that history is not a singular event, that its interpretation can be seen from different perspectives and thus how one historian explains a past event can be used to justify the courts' continued remaining within a neo colonialist process instead of looking anew at a history through different processes including the acceptance of traditional knowledge and oral history. 


\section{Chapter: Census Data and Geographic Distribution of Métis Peoples and Communities}

\subsection{Introduction}

As has been noted in the previous chapters, the notion of identity is difficult and fraught with notions of power, control and in Canada, a neo-colonialist imperative. Canadian policy makers have relied on Eurocentric interpretations of the history of Inuit, First Nation and Métis peoples in Canada and have used data collected by the state in coming to the decisions that impact the Aboriginal peoples in ways that have often been at the expense, both culturally and economically, of peoples already marginalized within the Canadian nation state. This in no small part is due to how the data are collected and analyzed (Hubner, 2007). Quantitative data are rightly identified as 'powerful persuaders' by Maggie Walter and Chris Anderson (2013: 7). This is especially true of population statistics, such as those generated by the Census of Canada. Walter and Anderson note,

Population statistics in particular are an evidentiary base that reflects and constructs particular visions considered important in and to the modern state. They map the very contours of the social world itself (2013:7)

This reflection and construction will be critically examined in this chapter especially in the use of statistics by the state, and primarily the Census of Canada, to define a cultural distinction in the Métis people that may represent an interest to itself and not the Métis. This chapter will not only explore the problems facing the use of census data but will show that it remains useful because it is the only source of quantifiable information available at this time. 
In looking at the reliance public institutions and policy makers have on data collected through a variety of means to help mold and determine public policy, Walter and Anderson note,

...the quantitative methodologies that guide the collection, analysis, and interpretation of data about Indigenous peoples both reflect and constitute, in ways largely invisible to their producers and users, the dominant cultural framework of the nation-state within which they (that is, statistics) operate. $(2013,9)$

This 'dominant cultural framework' can be seen as a remnant of colonial thought and attempts to control Indigenous populations through the application of definitions or as the case is with Métis, limitations in how people are allowed to identify themselves on a census form. This is part of a broader problem where there is limited recognition of Indigenous ways of seeing themselves and their place in the world, and how that place may be subjected to state control. These concerns are rooted in an Indigenous cosmological foundation articulated in a wide variety of writings by Indigenous scholars both within Canada and in other regions of the world. These writers share a history tied to a colonial past (and present) and associated actions by settler states, such as marginalization within the economic machinery of the dominant population, a loss of cultural identity often identified by a loss of language, and being subject to legislation that attempts to remove all traces of Indigenous state-hood (i.e., the Indian Act, residential schools, and son on), and as I argue, through the imposition of labels used in the national census.

This chapter examines the use of census data collected by Statistics Canada as a way of understanding who Métis are and where Métis are geographically located. It centers on how the census of Canada may be seen as being used to construct a Métis identity in a 
manner that suits the need of the greater nation state and not the needs of the Métis peoples or their political organizations. However, while the design of the census and use of census data are fraught with serious problems and require careful interpretation, the census remains the best available source of information to assess demographic changes and the distribution of Métis regions and communities in Canada.

The largest longitudinal and national level demographic data pertaining to Métis peoples in Canada is the Census of Canada (Jantzen, 2004; Saku, 1999; Wright, 1993). It is the single most significant source of demographic data on Aboriginal peoples.

The Canadian census is the most comprehensive source of demographic data on Aboriginal peoples in Canada, and is the exclusive source of demographic data for many Aboriginal groups (Guimond, Kerr and Beaujot, 2004: 62)

For this research national and provincial level data from 1996, 2001 and 2006 will provide a 'data story' on how the Métis population has changed over this period, and the consequences, if any, from the Powley decision will be pointed out. Along with tables which will pull out significant data sets to enhance the arguments of this research, some of these data sets will also be mapped to provide visual representations, including the notion that while there may be issues related to the notions of power and post-colonial control over indigenous peoples by the use of tools such as statistics, there may also be benefits through which data may be used to enhance the lives of indigenous peoples.

The decision to limit the main 'data story' to these three Census years, rests in their place within history related to the Powley decision. As well, significant changes to the ethnic origin question between 1986 and 1991, with a final format change occurring for the 1996 
census thus provides consistency in data between 1996, 2001 and 2006. The 1996 census also saw the addition of the self-identity question (Jantzen, 2013: 91). Finally data from 2011 which has become available at the time of writing is also be used on a limited basis.

While there are concerns with the census question related to Aboriginal identity and how it is asked (Cherubini, 008; Hubner, 2007; Walter and Anderson, 2013), the data collected still paints a useful, albeit partial, picture about peoples who have identified themselves as Métis, and that history needs to be acknowledged. Their pronouncement as Métis in the census record may or may not be an indication that they feel they have Aboriginal rights which must be recognized. A person's reasons for self-identifying as Métis when completing the census form are not recorded. Neither is it clear whether the people filling out the forms feel that the labels that they choose from are entirely appropriate. In addition, in terms of community, it is not always clear whether Métis living in the same census tract belong to a shared community, or whether they simply live within the same administrative boundaries. In many cases, additional information would be required to show that people identifying as Métis in any given area share a common history with others in that same geographical area. This would seem to be beyond the purpose of a census but might more easily be introduced in a survey such as the Aboriginal Peoples Survey collected by Statistics Canada, a survey conducted on a sample of those respondents who identified themselves as Aboriginal in the Census of Population. How Métis peoples would respond to what some might see as intrusive is unknown and could further create mistrust between Métis and the crown if the data being gathered are seen as enhancing the crown's position 
against Métis in activities such as court cases. In addition, the sample, being arbitrary, might not be an appropriate methodology for such an activity in its current form.

This chapter will also identify the limitations of the census, along with recommendations for further research that could help determine more appropriate ways of recognizing peoples who have been grouped under the "Métis" label, but who may feel that they do not belong to the Métis geographic homeland centered on the historic Red River valley of Manitoba.

\subsection{The Census of Canada - Overview}

The Census of Canada is a snapshot in time, collected every 5 years on a set date. All attempts are made to enumerate every person in Canada. For the purposes of this research only the data from the $2 \mathrm{~B}$ form, completed by 1 in 5 households, are used because the Aboriginal identity question only appears on this form. For the 2011 census significant changes were made. One item that was highly contentious was removing the mandatory response requirements of the census. While some aggregated datum have been released on the Métis demography, more detailed and disaggregated data below provincial totals were not available at the time of the writing of this thesis.

To extrapolate data collected in the 20 percent sample, Statistics Canada uses a regression estimation weighting procedure. This method ensures that the represented data can be seen as complete for the entire population. It should also be noted that in order to protect confidentiality provisions, data are rounded to make identification of individuals 
impossible. On larger population sets this rounding only impacts the quality of the data in a minor way, if at all. For smaller data sets, such as the Aboriginal population, the rounding of data may have a significant impact. As such, and this will be seen in the data analysis that follows, some arbitrariness has been put into the selection of populations within census sub-divisions based on the size of the enumerated population. Again this takes into account the need for a broad definition of who is Métis and by extension whether or not a mixed ethnicity Aboriginal community is Métis.

In this research I also consider why some individuals may continue to resist selfidentification or arbitrarily may seem to identify with one community one census year and another community the following year. In answering the first question, we must recognize the continued mistrust inherent in data collection by the state. In speaking on this same issue for First Nation peoples Hubner (2007: 204) writes,

Perry Bellegarde, regional chief for Saskatchewan for the Assembly of First Nations said the census [the 2001 census] remained an intrusive reminder of broken treaties. It is just another survey, study, and set of statistics, which made no improvement in the lives of First Nations: "So our people are very skeptical of those processes." (Janzen 2002).

With respect to population adjustments or shifts between census years, there may be a competing interest by individuals who claim First Nation or identity one census year then Métis identity in a subsequent census. These varied identity claims may be the result of 'race shifting' as defined by Circe Sturn (2002) or as 'ethnic drift' (Guimond, 2003. This will be further discussed below. 
The 2006 Census of Canada questionnaire places the following question to respondents: "Is this person an Aboriginal person, that is, a North American Indian, Métis or Inuit (Eskimo)" which appeared as follows:
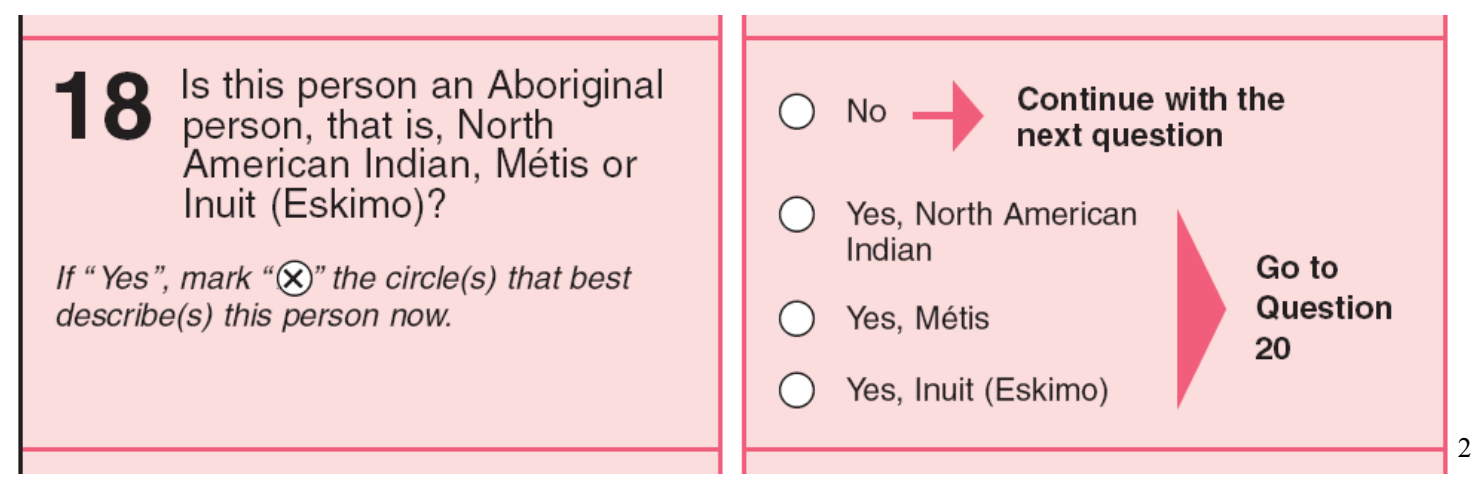

Self-identification offers both benefits and disadvantages. A benefit is that no arbitrary filtering is done to decide is one if a member of a population. It is personal and based on individual choice. It is “self-perception: that is, how one positions one's self in relation to (that) ancestry" (Walter and Anderson, 2013: 30)

In terms of negatives, self-identity does not provide controls on who indicates they are Aboriginal which in and of itself may not be an issue but used by expert witnesses in providing testimony to support the courts' rulings as is the case for Métis rights cases. These adjustments can allow a court an ability to deny any unique or sui generis attributes to a community which then may be used by governments to justify their stance on a particular Métis rights matter. To expand further with a hypothetical example, let us consider an area where a carrying capacity for traditional harvesting might be seen to be

\footnotetext{
${ }^{2}$ Image capture taken from http://www.statcan.gc.ca/imdb-bmdi/instrument/3901_Q2_V3-eng.pdf; accessed November 23, 2010
} 
$10 \%$ of the population. That is, $10 \%$ of the people living in the area could harvest without an immediate impact on the wildlife population. This percentage would be based on the total allowable harvest with consideration for the available number of harvesters. If that number, through self-identification rises to $20 \%$, that is a $10 \%$ increase in eligible harvesters assumed to be seeking to conduct harvesting in the area in addition to the original population. Under such circumstances, government might be justified in limiting the harvest through what would be an infringement on harvesting rights, to better ensure a healthy and viable wildlife population. My argument is that through the arrival of an increased population as a result of individuals now identifying themselves as part of a rights based community, a government can use the sudden population increase as a justification for limiting or terminating a harvest.

\subsection{Methodology: Managing the Data}

To arrive at the stated goal of identifying contemporary Métis communities, two phases of research were undertaken that together answer the question of whether Métis communities can be determined by the use of census records. The first phase includes the framing of the issue of identity related to Métis and the document review, which involved analyzing both contemporary and archival material. Next analysis of the 2006 Census of Canada formed the quantitative research phase in order to achieve the stated goals of this paper. For this component of the research, Statistics Canada 2001, 2006 and 2011 Census data are used at the census sub-division level to identify population clusters of identifiable Métis communities, providing an analysis of changes in Métis population before and after the Supreme Court of Canada decision in R. v. Powley. The census sub division is the preferred 
geographic extent for this research as it approximates the special extent or geography of Indian reserves and small towns which could result in a level of population exclusivity for Métis (Siggner et al., 2001). that is, where the Métis population is of such a size in comparison to other Aboriginal and non-Aboriginals people that the Métis are the most populous group. In addition to mapping, analysis of the Census of Canada 2001, 2006 and 2011 data was conducted to provide an overview of Métis populations across the country. Census data from 2001 were used to provide the baseline in a pre-Powley decision analysis of community evolution. In addition available 2011 Census data were used to provide a longitudinal view of the data.

The question of why Métis community identification should matter might be raised at this point as there may seem to be a bit of a discrepancy here that is confusing to the reader, and that should probably be explicitly noted. For Statistics Canada, you can be Métis through self-identification but for the courts, you also need to belong to a contemporary Métis community. This is an example of how different branches of the state don't have a single, monolithic way of dealing with identity issues and the complexity that is dealt with by researchers working on this subject matter.

In 2008 data work conducted for AANDC by a private consultation firm ${ }^{3}$ shows that the use of population data using the Aboriginal identity question may be sufficient in determining Métis communities. In their analysis population counts at the relatively small

\footnotetext{
${ }^{3}$ AANDC provided access to view the initial work as part of my research to complete the thesis but data was not made available due to the draft nature of the research at the time.
} 
census tract level were used, while analysis for this research looked at Métis population as a percentage of total population within any given census sub-division. While the methodology of the AANDC offers an alternative to the one presented here, it is limited in application since it deals exclusively with census tract datasets which can only be applied to urban areas. The use of the census sub-division data offers a better interpretation as to the location of contemporary Métis communities that are found outside of cities.

At a larger scale, mapping Métis populations using census data, identifying CSDs where at least $75 \%$ of the population identifies as Métis suggests that there are core areas with smaller Métis populations and lower percentages radiating away from them. Census subdivisions or CSDs, are defined as part of a lexicon where,

Census subdivision is a general term for municipalities as determined by provincial or territorial legislation, or areas treated as municipal equivalents for statistical purposes (e.g., Indian reserves, Indian settlements and unorganized territories). Municipalities are units of local government.” (Statistics Canada, 20012; 9)

While a number of initial observations were made during the mapping process and will be spoken to below, one item which did emerge but which is beyond the scope of this work arose in mapping this data within a Geographic Information System. Patterns emerged where CSDs with a significant percentage of Métis population appeared to act as a core with smaller population percentages radiating through the periphery in diminishing population percentages. While further research and data analysis will be conducted on this process, there appears to be spatial regularity that could lead to a clearer identification of contemporary Métis communities. This then acts as a starting point which can further be tested to identify Métis communities. 
Analysis of the 2006 and 2001 data also provided an analysis of population change that could likely have resulted through the "attitude shift" that occurred as a result of the SCC Powley decision in 2003 , where persons who previously did not self-identify or selfidentified as non-status on Census questionnaires in 2001 decided to identify as Métis in 2006. A dramatic population increase occurred, and exceeds the normal population changes that would be expected in a population (Guimond, 2003). This population increase may be attributed to the process of 'ethnic drift' (Guimond, 2003) and can be compared to a similar occurrence in the 1980s with the introduction of Bill C-31 and changes to the Indian Act, which affected the Registered Indian and non-status Indian population counts. In this case, persons who had previously indicated Aboriginal identity as Métis or Non-Status Indian may have re-defined themselves as Status Indians if the Department of Indian Affairs accepted their Indian Status application under the new legislation. It should be noted that while this ethnic shift to First Nation resulted from an amendment to legislation allowing for the growth of the population, for the situation we find occurring in the 2006 Census, there was no comparable decrease in the non-status Indian population counts. Thus the only source for this increased Métis population would be that individuals who previously did not identify as Aboriginal are now claiming or noting their Métis heritage. I raise this item here as the linkage between the two events may provide deeper insight in a comparison related to ethnic drift (Guimond, 2003). 


\subsection{Census Data: An overview of Census Data}

The percentage of individuals identifying as Métis in Canada between the 1996 Census and the most recent Census of 2011 has remained constant at just under 1\% Métis identity to total Canadian population. Within the Métis population, however there have been dramatic increases in population as is shown in Table 1. In relation to the percentage of individuals identifying as Métis to those who identify with one of the three Aboriginal categories, percentages increased between 2001 and 2006 at both the national level and in all provinces but Newfoundland and Labrador, New Brunswick and the Northwest Territories. Between 2006 and 2011 those percentages either remained stable or dropped suggesting a possibility that removing other factors, the Powley decision resulted in a greater number of individuals who previously did not self-identify as Métis doing so in 2006 (Table 1). The exception of the drop in 2011 was in Nunavut but its small population of Métis suggests an increase may have been due to rounding or other easily explained factors.

Moving forward to the 2011 census, according to the census data the Métis population grew dramatically between 1996 to 2011, more than doubling to almost half a million people (Table 1). If this were attributable to natural increase alone, it would have required extremely high fertility rates and low mortality rates resulting in an average annual increase of over 5 percent.

In the 2011 census, 1,400,685 individuals identified as Aboriginal. This total includes 851,560 First Nations peoples, 451,795 Métis and 59,445 identifying as Inuit. Aboriginal 
peoples account for $4.3 \%$ of the total population and increased from $2.8 \%$ of the total population in 1996. Of the total Aboriginal population in 2011, First Nations peoples represent $60.8 \%$ while Métis represent $32.25 \%$ and Inuit $4.24 \%$ of the population.

In the period between 1996 and 2011 the largest increase in Métis population occurred in the three Maritime Provinces, the largest single growth occurring in Nova Scotia with a 91.7\% increase between 1996 and 2011 in the population identifying as Métis.

As Saku notes, changes in the wording of the census questionnaire during the 1980s and 1990s needs to be considered when these data sets are compared (Saku, 1999: 371).

The most dramatic increase in the Métis population figures occurs between 1991 and 2006. It is unlikely that this is attributable to high fertility rates. As has been discussed by Guimond (2013) a population increase of this magnitude is beyond what could be expected from any naturally occurring population increase cycle. Similarly with the court's decision in Powley, individuals of Métis ancestry who had previously not publically identified as Métis due to concerns they may have had relating to prejudicial treatment by others, may now be willing to identify as Métis due to the growing sense of pride in Métis identity. These thoughts are based on conjecture and little research can be found in why people would assume an identity that they had once hidden or remained silent on. 
Table 1 - Métis population by province

\begin{tabular}{|l|l|l|l|l|l|l|l|l|}
\hline Geography & $\mathbf{1 9 9 6}$ & $\mathbf{2 0 0 1}$ & $\begin{array}{l}\mathbf{\%} \\
\text { increase } \\
\text { between } \\
\mathbf{1 9 9 6 -} \\
\mathbf{2 0 0 1}\end{array}$ & $\mathbf{2 0 0 6}$ & $\begin{array}{l}\mathbf{\%} \\
\text { increase } \\
\text { between } \\
\mathbf{2 0 0 1 -} \\
\mathbf{2 0 0 6}\end{array}$ & $\mathbf{2 0 1 1}$ & $\begin{array}{l}\text { \% } \\
\text { increase } \\
\text { between } \\
\mathbf{2 0 0 6} \\
\mathbf{2 0 1 1}\end{array}$ & $\begin{array}{l}\text { increase } \\
\text { between } \\
\mathbf{1 9 9 6} \\
\mathbf{2 0 1 1}\end{array}$ \\
\hline Métis Canada \\
\hline $\begin{array}{l}\text { Newfoundland } \\
\text { and Labrador }\end{array}$ & 204,115 & 292,305 & $43.21 \%$ & 389,785 & $33.35 \%$ & 453,790 & $16.42 \%$ & $122.32 \%$ \\
\hline $\begin{array}{l}\text { Prince Edward } \\
\text { Island }\end{array}$ & 110 & 220 & $100 \%$ & 385 & $75 \%$ & 410 & $6.49 \%$ & $272.73 \%$ \\
\hline Nova Scotia & 830 & 3,135 & $277.71 \%$ & 7,680 & $144.98 \%$ & 10,050 & $30.86 \%$ & $1110.84 \%$ \\
\hline $\begin{array}{l}\text { New } \\
\text { Brunswick }\end{array}$ & 950 & 4,295 & $352.11 \%$ & 4,270 & $-0.58 \%$ & 4,850 & $13.58 \%$ & $410.53 \%$ \\
\hline Quebec & 15,560 & 15,850 & $1.86 \%$ & 27,980 & $76.53 \%$ & 40,960 & $46.39 \%$ & $163.24 \%$ \\
\hline Ontario & 21,525 & 48,340 & $124.58 \%$ & 73,605 & $52.27 \%$ & 86,015 & $16.86 \%$ & $299.61 \%$ \\
\hline Manitoba & 45,360 & 56,795 & $25.21 \%$ & 71,805 & $26.43 \%$ & 78,835 & $9.79 \%$ & $73.80 \%$ \\
\hline Saskatchewan & 35,855 & 43,695 & $21.87 \%$ & 48,120 & $10.13 \%$ & 52,450 & $9 \%$ & $46.28 \%$ \\
\hline Alberta & 49,495 & 66,060 & $33.47 \%$ & 85,495 & $29.42 \%$ & 98,870 & $15.64 \%$ & $99.76 \%$ \\
\hline $\begin{array}{l}\text { British } \\
\text { Columbia }\end{array}$ & 25,575 & 44,265 & $73.08 \%$ & 59,445 & $34.29 \%$ & 69,470 & $16.86 \%$ & $171.63 \%$ \\
\hline Yukon & 550 & 535 & $-2.73 \%$ & 800 & $49.53 \%$ & 845 & $5.63 \%$ & $53.64 \%$ \\
\hline $\begin{array}{l}\text { Northwest } \\
\text { Territories }\end{array}$ & 3,750 & 3,575 & $-4.67 \%$ & 3,580 & $0.14 \%$ & 3,245 & $-9.36 \%$ & $-13.47 \%$ \\
\hline Nunavut & & 50 & $n / a$ & 130 & $160 . \%$ & 130 & $0.00 \%$ & $100 \%$ \\
\hline
\end{tabular}

As Table 1 illustrates, there is some level of consistency across the years that may indicate population growth levels were the result of natural growth and not specifically due to a 'jumping on the band wagon' to declare Métis-ness as Anderson has argued (Anderson, 2008). This then shows the complexity in not only Métis identity but the fluid nature of identity in general. 
As Table 1 shows, in 2006 the majority (about 4 in 5) of Métis resided west of the Province of Quebec. This is similar to the population distribution with people who identify as First Nations where fewer than 102,000 reside in the Province of Quebec and Atlantic Provinces while close to 600,000 reside in Ontario, the Prairie Provinces and British Columbia.

In analyzing census data for Métis the issue of underrepresentation has not been thoroughly discussed by demographers or statisticians to the level that First Nation under coverage has been discussed (Statistics Canada, 2007). Based on an analysis of the difference in population counts between the 2001 Census of Population and the populations for the nonenumerated reserves found in the Department of Indian Affairs Band Registry, an estimate of $5 \%$ undercount was determined. It is possible that a similar undercount is applicable to the Métis population counts.

Table 2 highlights the largest Métis population percentages of over 50\% of total population in the census sub-division under examination, from the 2001 Census of Population. 
Table 2-2001 Métis populations in select CSDs

\begin{tabular}{|l|l|l|l|l|}
\hline Geography & Province & $\begin{array}{l}\text { Total } \\
\text { Population }\end{array}$ & $\begin{array}{l}\text { Métis } \\
\text { Population }\end{array}$ & $\begin{array}{l}\text { \% Métis to total } \\
\text { Population }\end{array}$ \\
\hline $\begin{array}{l}\text { Ile-a-la-Crosse } \\
\text { Charlottetown } \\
\text { (Labrador) }\end{array}$ & Saskatchewan & 1255 & 1095 & 87.25 \\
\hline $\begin{array}{l}\text { Port Hope } \\
\text { Simpson }\end{array}$ & NFLD & 345 & 295 & 85.51 \\
\hline Green Lake & Saskatchewan & 500 & 435 & 85.29 \\
\hline Beauval & Saskatchewan & 840 & 415 & 83.00 \\
\hline Pinehouse & Saskatchewan & 1040 & 695 & 82.74 \\
\hline $\begin{array}{l}\text { Division No. } \\
\text { 10 Subd. B }\end{array}$ & $\begin{array}{l}\text { Newfoundland } \\
\text { and Labrador }\end{array}$ & 490 & 855 & 82.21 \\
\hline Turnor Lake & Saskatchewan & 155 & 120 & 80.61 \\
\hline $\begin{array}{l}\text { Cartwright } \\
\text { Labrador) }\end{array}$ & $\begin{array}{l}\text { Newfoundland } \\
\text { and Labrador }\end{array}$ & 630 & 465 & 77.42 \\
\hline $\begin{array}{l}\text { Buffalo } \\
\text { Narrows }\end{array}$ & Saskatchewan & 1135 & 835 & 73.81 \\
\hline $\begin{array}{l}\text { St. Lewis } \\
\text { and Labrador }\end{array}$ & 290 & 200 & 73.57 \\
\hline $\begin{array}{l}\text { Mary's } \\
\text { Harbour }\end{array}$ & $\begin{array}{l}\text { Newfoundland } \\
\text { and Labrador }\end{array}$ & 450 & 265 & 68.97 \\
\hline La Loche & Saskatchewan & 2135 & 1235 & 58.89 \\
\hline $\begin{array}{l}\text { Cumberland } \\
\text { House }\end{array}$ & Saskatchewan & 630 & 360 & 57.85 \\
\hline St. Laurent & Manitoba & 1155 & 660 & 57.14 \\
\hline Jans Bay & Saskatchewan & 195 & 105 & 53.85 \\
\hline Cole Bay & Saskatchewan & 160 & 85 & 53.13 \\
\hline Park (North) & Manitoba & 335 & 170 & 50.75 \\
\hline & & & \\
\hline
\end{tabular}

Of particular note, and an example of the use of CSD data to determine communities, is the strength of the populations in the Labrador CSDs. The communities of Charlottetown, Port Hope Simpson, Cartwright, St. Lewis and Mary's Harbour are located along the Labrador Coast. These communities are known locally as Labrador Métis communities and more recently make up the communities of the NunatuKavut Community Council. 
The existence of these communities which self-identify as Labrador Métis highlights the existence of a cohesive community of "mixed blood" peoples who share a common history and identify as Métis existing in Labrador. The high population percentage also can be associated with a strong sense of community pride by the Labrador Métis political leadership and may have contributed to the successful litigation in 2006 identified earlier in this research.

Table 3-2006 Métis populations in select CSDs

\begin{tabular}{|l|l|l|l|l|}
\hline Geography & Province & Total Population & Métis identity & $\begin{array}{l}\text { \% Métis to total } \\
\text { population }\end{array}$ \\
\hline Green Lake NV & sask & 360 & 300 & 83.33 \\
\hline $\begin{array}{l}\text { Charlottetown } \\
\text { (Labrador) T }\end{array}$ & NFLD & 365 & 300 & 82.19 \\
\hline $\begin{array}{l}\text { Ile-à-la-Crosse } \\
\text { NV }\end{array}$ & sask & 1335 & 1095 & 82.02 \\
\hline Beauval NV & sask & 830 & 680 & 81.93 \\
\hline Pinehouse NV & sask & 1075 & 855 & 79.53 \\
\hline $\begin{array}{l}\text { Port Hope } \\
\text { Simpson T }\end{array}$ & NFLD & 530 & 420 & 79.25 \\
\hline $\begin{array}{l}\text { Buffalo Narrows } \\
\text { NV }\end{array}$ & sask & 1080 & 810 & 75.00 \\
\hline $\begin{array}{l}\text { Cartwright } \\
\text { Labrador T }\end{array}$ & NFLD & 550 & 410 & 74.55 \\
\hline $\begin{array}{l}\text { Cumberland } \\
\text { House NV }\end{array}$ & sask & 810 & 570 & 70.37 \\
\hline St. Lewis T & NFLD & 255 & 175 & 68.63 \\
\hline $\begin{array}{l}\text { Division No. 10 } \\
\text { Subd. B SNO }\end{array}$ & NFLD & 475 & 325 & 68.42 \\
\hline Makwa VL & sask & 95 & 65 & 68.42 \\
\hline Jans Bay NV & sask & 180 & 120 & 66.67 \\
\hline $\begin{array}{l}\text { Mary's Harbour } \\
\text { T }\end{array}$ & NFLD & 410 & 240 & 58.54 \\
\hline Cole Bay NV & sask & 160 & 90 & 56.25 \\
\hline La Loche NV & sask & 2340 & 1240 & 52.99 \\
\hline St. Laurent RM & man & 1445 & 745 & 51.56 \\
\hline Park (North) RM & man & 285 & 145 & 50.88 \\
\hline
\end{tabular}

In comparing Tables 2 and 3, there are two important points to highlight. The first is in the consistency between census years for CSDs in Saskatchewan and Labrador to maintain communities that have a high population of Métis to non-Métis percentage. This may speak to a strong sense of identity and community cohesion. The second is that while some CSDs 
saw extreme growth in Métis identity populations and this was seen by some researchers as a fluidity within the Aboriginal population moving from one identity to another in census years (Guimond, 2003) the reality is that in these predominately Métis communities, population changes are seen within the total population at the provincial level. This may suggest that these communities are more stable and not subject to identity recognition fluctuations that may follow significant court decision as has been inferred by Guimond in the concept of ethnic mobility (2003).

In further analyzing the data it should be noted that a significant proportion of the Métis population reside in Census Metropolitan Areas (CMA) with Winnipeg, Edmonton and Vancouver having the largest Métis urban populations in Canada. This is relevant since it highlights the mobility of Aboriginal peoples into urban centers, although it should be noted that many Western urban centers in particular were the original homelands for Métis who tended to develop communities around former trading posts (Innis, 1930; Podruchny, 2006; Ray, 2005). Table 3 provides a breakdown for these CMAs. 
Table 4 Métis population in select CMA's

\begin{tabular}{|c|c|c|c|c|c|c|c|c|c|}
\hline Geography & $\begin{array}{l}2001 \text { Total } \\
\text { Population }\end{array}$ & $\begin{array}{l}2001 \\
\text { Aboriginal } \\
\text { Identity* }\end{array}$ & 2001 Métis & $\begin{array}{l}2006 \text { Total } \\
\text { Population }\end{array}$ & $\begin{array}{l}2006 \\
\text { Aboriginal } \\
\text { Identity }\end{array}$ & $\begin{array}{l}2006 \\
\text { Métis }\end{array}$ & $\begin{array}{l}2011 \text { Total } \\
\text { Population }\end{array}$ & $\begin{array}{l}2011 \\
\text { Aboriginal } \\
\text { Identity }\end{array}$ & $\begin{array}{l}2011 \\
\text { Métis }\end{array}$ \\
\hline Winnipeg & 671,275 & 55,760 & 31,390 & 686,035 & 68,385 & 40,980 & 714,640 & 78,415 & 46,070 \\
\hline Edmonton & 927,020 & 40,930 & 21,065 & $1,024,825$ & 52,100 & 27,740 & $1,139,580$ & 61,770 & 31,780 \\
\hline Vancouver & $1,967,475$ & 36,855 & 12,505 & $2,097,960$ & 40,310 & 15,075 & $2,280,695$ & 53,375 & 18,485 \\
\hline Calgary & 943,310 & 21,910 & 10,575 & $1,070,295$ & 26,575 & 14,770 & $1,199,925$ & 33,370 & 17,040 \\
\hline Saskatoon & 222,635 & 20,275 & 8,305 & 230,855 & 21,535 & 9,610 & 256,435 & 23,890 & 11,515 \\
\hline Ottawa-Gatineau & $1,050,755$ & 13,485 & 4,695 & $1,117,125$ & 20,590 & 7,990 & $1,215,735$ & 30,570 & 12,265 \\
\hline Toronto & $4,647,955$ & 20,300 & 5,095 & $5,072,070$ & 26,575 & 7,580 & $5,521,235$ & 36,990 & 9,980 \\
\hline Regina & 190,015 & 15,685 & 5,995 & 192,435 & 17,105 & 7,185 & 207,215 & 19,785 & 8,225 \\
\hline Prince Albert, CA & 39,890 & 11,640 & 5,945 & 39,800 & 13,570 & 6,680 & 40,955 & 15,780 & 7,905 \\
\hline Montreal & $3,380,640$ & 11,090 & 3,665 & $3,588,520$ & 17,865 & 6,010 & $3,752,475$ & 26,285 & 8,840 \\
\hline Greater Sudbury & 153,560 & 7,065 & 3,310 & 153,395 & 9,970 & 5,430 & 158,260 & 13,410 & 6,455 \\
\hline
\end{tabular}


In looking at the Winnipeg CMA data over the three census periods, the Métis population increased by over 23\% between 2001 and 2006 but only increased by $11 \%$ between 2006 and 2011. This is comparable to population change for the total Aboriginal population over the same period. As well, the total population counts for Winnipeg have similar population percentage increases. This trend seems to indicate that the Métis population changes are in line with those of the whole community. In considering Guimond's ethnic drift concept in the urban communities, it may not be as applicable as it is for rural areas. We may ask why this may be the case. Without further research only conjecture would provide a response at this point. This does though point to a value of census data in that if Métis population increase and decrease for a geographic area such as in urban centres, is somewhat stable (if compared to the overall population increase and population percentages), socioeconomic support can more easily be identified to support those Métis peoples who may require social support services. For total population in Winnipeg, the statistics indicate an increase by $11 \%$ for Métis, with a total population rising by just over $2 \%$ in the period between 2001 and 2006 and then 12\% and 4\% respectively for 2006 to 2011. These percentages, which are much lower than the overall increases at the national scale, seem to further indicate ethnic drift may not occurring here as it may be elsewhere.

Of note on the Aboriginal population living in urban areas, the data indicate that in 2011 $71 \%$ of the Métis identity population and $75 \%$ of the non-status Indian population resided in urban centers. This population may find greater difficulty in proving Métis rights for two specific reasons. The first is that the courts may see the population density of Métis as too low as to constitute a distinct Métis community within an urban centre. As Métis would only represent a small percentage of the total population, its ability to establish a critical 
mass for community might be questioned. This notion would be offset if the courts adopt a more liberal interpretation of what can be considered a "community."

Second, the movement by Métis away from traditional territories into urban centers may also result in a diminished sense of identity. As Marie Battiste and James (Sa'Ke'j) Youngblood Henderson state,

From the beginning, the forces of the ecologies in which we live have taught Indigenous peoples a proper kinship order and have taught us how to have nourishing relationships with our ecosystems. The ecologies in which we live are more to us than settings or places; they are more than homelands or promised homelands. These ecologies do not surround Indigenous peoples; we are an integral part of them and we inherently belong to them. The ecologies are alive with the enduring processes of creation itself. As Indigenous peoples, we invest the ecologies with deep respect, and from them we unfold our structure of Indigenous life and thought. $(2000,9)$

This relationship or more appropriately kinship, with a traditional territory may be lost by many urbanized Métis. Certainly some urban areas lie within the traditional territories of some Métis communities, but what is being discussed here will apply to a large number of Métis who move outside their territories for the opportunities that lie within urban centers. Additionally arbitrary historic linkage between historic and contemporary Métis communities will be more difficult to prove for the Métis in large urban settings where that connection has been erased from the Euro-Canadian history books and where the traditional knowledge of Métis is seen as something of the past with no place in a 'modern' urban community.

\subsection{Mapping and Métis population}

There is no single, standard method for mapping Métis communities using census data in a way that attempts to reflect legal requirements put forward by the courts. Here I explore the possibility of doing this, and offer three alternative options which are further described 
below. All three approaches have limitations in that they are subject to changes in the identity response rate which as shown in the previous sections of this chapter cannot be attributed to either natural growth or fluctuation in response rates due to ethnic drift or some other migration from assuming one identity then another from census period to census period.

Table 5 summarizes the 50 largest Métis population CSDs based on the 2006 census. The location of these CSDs in some of Canada's largest metropolitan areas confirms the findings discussed above that highlights Métis settlement within urban areas.

In an attempt to identify and map Métis communities, the first step was to select all CSDs with a population of at least 30 individuals who self-identified as Métis during the 2006 census. This would remove possible rounding up of the data and provide a suitable base population for the purposes of this research. In total there were 5418 CSDs in the 2006 census of which 2303 CSDs had a Métis population. As a first step, these CSDs were mapped using centroid points instead of the CSD polygon to assist in readability of the mapped data. 
Table 5 - Largest Métis CSDs 2006

\begin{tabular}{|c|c|c|c|}
\hline Geography 2006 & $\begin{array}{ll}\text { Total } & \text { Population } \\
2006 & \end{array}$ & $\begin{array}{l}\text { Aboriginal } \\
\text { population } 2006\end{array}$ & $\begin{array}{l}\text { Métis identity only } \\
2006\end{array}$ \\
\hline Winnipeg CY & 625700 & 63745 & 37390 \\
\hline Edmonton CY & 722260 & 38170 & 20690 \\
\hline Calgary CY & 979485 & 24425 & 13505 \\
\hline Saskatoon CY & 199385 & 19820 & 8610 \\
\hline Regina CY & 176915 & 16535 & 6855 \\
\hline Prince Albert CY & 33445 & 12140 & 5835 \\
\hline $\begin{array}{l}\text { Greater Sudbury / } \\
\text { Grand Sudbury C }\end{array}$ & 155995 & 9590 & 5425 \\
\hline Ottawa C & 801275 & 12245 & 4495 \\
\hline Surrey CY & 392450 & 7630 & 3705 \\
\hline Toronto $\mathrm{C}$ & 2476565 & 13605 & 3650 \\
\hline Prince George CY & 70375 & 8045 & 3595 \\
\hline Vancouver CY & 571600 & 11145 & 3235 \\
\hline Sault Ste. Marie CY & 73895 & 5980 & 2910 \\
\hline Montréal V & 1593725 & 7600 & 2645 \\
\hline Grande Prairie CY & 46755 & 4360 & 2605 \\
\hline Gatineau V & 239980 & 6270 & 2595 \\
\hline Wood Buffalo RGM & 51410 & 5360 & 2535 \\
\hline Red Deer CY & 81370 & 3600 & 2530 \\
\hline Thunder Bay CY & 107290 & 8850 & 2165 \\
\hline Kamloops CY & 79440 & 5165 & 2145 \\
\hline Big Lakes MD & 5805 & 2930 & 2030 \\
\hline Kelowna CY & 105175 & 3600 & 1865 \\
\hline Brandon CY & 40705 & 3995 & 1760 \\
\hline Halifax RGM & 369265 & 5230 & 1755 \\
\hline Abbotsford CY & 122175 & 3565 & 1735 \\
\hline Selkirk CY & 9010 & 2460 & 1710 \\
\hline Timmins CY & 42455 & 3280 & 1690 \\
\hline North Bay CY & 53240 & 3205 & 1615 \\
\hline Hamilton $\mathrm{C}$ & 497395 & 7630 & 1530 \\
\hline Thompson CY & 13400 & 4910 & 1505 \\
\hline Nanaimo CY & 77630 & 4060 & 1450 \\
\hline $\begin{array}{l}\text { Strathcona County } \\
\text { SM }\end{array}$ & 81845 & 2270 & 1435 \\
\hline $\begin{array}{l}\text { Bonnyville No. } 87 \\
\text { MD }\end{array}$ & 10170 & 1815 & 1420 \\
\hline Medicine Hat CY & 55950 & 2130 & 1400 \\
\hline Yellowknife CY & 18510 & 4105 & 1385 \\
\hline Windsor CY & 214255 & 3960 & 1350 \\
\hline $\begin{array}{l}\text { Happy Valley- } \\
\text { Goose Bay T }\end{array}$ & 7470 & 2720 & 1320 \\
\hline Langley DM & 93035 & 2455 & 1320 \\
\hline $\begin{array}{l}\text { Portage la Prairie } \\
\mathrm{CY}\end{array}$ & 12105 & 2575 & 1315 \\
\hline Chilliwack CY & 68670 & 3400 & 1310 \\
\hline Saguenay V & 141680 & 2215 & 1240 \\
\hline La Loche NV & 2340 & 2225 & 1240 \\
\hline $\begin{array}{ll}\text { Division No. } & 19 \\
\text { Unorganized NO } & \end{array}$ & 3210 & 2440 & 1235 \\
\hline The Pas T & 5520 & 2245 & 1190 \\
\hline Argyle MD & 8595 & 1280 & 1185 \\
\hline Kenora CY & 14950 & 2365 & 1175 \\
\hline Midland T & 16000 & 1415 & 1105 \\
\hline Dauphin CY & 7740 & 1505 & 1105 \\
\hline Île-à-la-Crosse NV & 1335 & 1245 & 1095 \\
\hline Meadow Lake T & 4680 & 1865 & 1090 \\
\hline
\end{tabular}


Mapping of 2006 Census Sub Division (CSD) tabular data were linked with CSD polygon shapefiles using the CSD unique identifier. Those CSDs with at least 30 Métis respondents were identified as an arbitrary starting point for a sustainable Métis community not limited to a single family unit or rounding of data, and a centroid point for each polygon was created for mapping.

Initially CSD points where a population greater than 30 individuals who indicated they were Métis were identified and provided the base map for the remainder of the analysis. The nature of the distribution is not sufficient at the level of this map to analyze density of Métis populations but only shown here to indicate the scope of Métis identity respondents across the country within larger populations found in most urban centers in Canada. This alone suggests Métis population concentrations in census metropolitan areas as a future study point.

In looking at one example of the concentration of Métis identity respondents in a large metropolitan center, Winnipeg with the largest number of identity respondents was selected. Map 1 show 2006 census tract data with the concentration of Métis identity respondents along the core of the city predominantly in the area known as the forks, as well as to the east of the current center of the City of Winnipeg. This research does not delve into the socio economic characteristics of Métis respondents to determine if there is a relationship between spatial distribution and socio economic factors but there may be a relationship between these factors that goes beyond a mere identity relationship.

In order to determine if the concentrations identified in Maps 2 and Map 3 were legitimate to be considered potential areas for distinct Métis communities, a further analysis of the 
data was considered. Using just the Aboriginal identity population data, those CSDs with a total Aboriginal population with $25 \%$ or more of the total population identifying as Aboriginal were selected. CSDs identified as Indian Reserves were removed as the very creation of a reserve is to place or settle people of First Nation ancestry within a specific concentrated geographic region while at the same time placing possible limits to the settlement in the area by non-First Nation peoples.

In those CSDs with a total Aboriginal population equal to or exceeding $25 \%$ of the total population a further analysis was made to find CSDs where the total Métis population was equal to or exceeded $25 \%$ of the Aboriginal population. These larger communities represent a clear opportunity for a contemporary Métis population within those CSDs regardless of the population's size since community cohesion and a community identity can develop in a larger concentrated population. I would also suggest that this larger Métis population within the context of a total Aboriginal population also provides for a Métis community identity to develop distinct from that of the First Nation or Inuit community. This would provide for a level of self-determination with less influence by outside organizations, especially the federal government, who might have the capacity and context to work with First Nation or Inuit communities while ignoring Métis issues. This will continue to be the case until a firm recognition of federal responsibility for Métis becomes the norm within government operations and policies.

It is evident that the data on the following pages suggests patterns within the census data where census metropolitan areas identified in table 4 reveal a core around which individuals who claim Métis identity are found in population concentrations that could be considered Métis communities, as required in the Powley test to confirm Métis rights. The 
advantage of using the data for preliminary analysis may be beneficial equally to the courts, the Crown and the Métis people who rely on quantitative data information that is not available from any other source.

As table 5 noted above, Métis identity respondents are found in larger numbers within urban centers. This may be the result of a number of factors including the geographic locations being part of an original settlement, the lack of Métis reserves (the exception being in Alberta where there are eight Métis Settlements which were established under provincial legislation in 1938), or socio economic factors which see individuals and families migrate from areas of limited employment opportunities to larger urban centers in the hope of finding work. Whatever the reason, there is no doubt that Métis communities can exist in urban centers due to the number of individuals providing a critical mass.

Maps 4, 5 and 6 portray the census data through three different classifications. The first of this series, Map 4 shows the CSDs with simple population breaks as classification values. It shows larger Métis population numbers in dark blue associated with the larger urban centers, often on the periphery. Map 5 shows the percentage of Métis in relation to the total population in the CSD. Classification was based on natural breaks. While Métis populations are significantly smaller than the total population in any given urban CSD, there is still a clear critical mass established to suggest the existence of a Métis community. Finally Map 7 simply offers a different view of Map 6 where Métis are compared to the total Aboriginal population by percentage. Again we see indications that the Métis are concentrated in specific areas and have a significant presence in urban centers in comparison to First Nation or Inuit identity respondents. 
The use of CSD data without some form of filtering would likely result in CSDs being considered as locations where Métis populations are either nonexistent or too small to be considered as viable communities. It should be stated again, that CSD level data offers researchers the best available data scale for the work of identifying Métis communities.

Data interpretation shows that there are some extensive Métis population CSDs, with smaller Métis populations flowing away from these density areas such as in the area around North Bay Ontario. Map 7 provides a visual representation of the data resulting in what could be described as a 'core-periphery model' based on Freidman's work in 1966 (Raagmaa, 2003).

The data analysis points out 'concentrations' where a significant population has identified as Métis. This in turn may indicate a viable community based on a pattern such as that found in the North Bay region, if it is seen occurring elsewhere in the country. The other link which would need to be examined in future research is locating former trading posts and mapping CSD population density to identify if there is a relationship between the two topics. A very basic interpretation, and knowledge of the area around North Bay, suggests that in fact, contemporary Métis populations are located in historically settled areas which where economic hubs for the surrounding regions.

\subsection{Concluding thoughts}

While some might question whether the census data may be the most appropriate method to track whether or not contemporary Métis communities exist, there can be no doubt that there is value to use census data to provide a first level view of general characteristics of Métis demography as well as an initial determination as to where contemporary Métis 
communities may be found. Equally important is that census data in urban areas provides

a framework for researchers to identity socio-economic issues facing Métis peoples that marginalize them more profoundly in these urban areas. As Peters states,

Understanding urban Aboriginal identities is important to public policy in Canada. As recent census results show, increasingly the Canadian Aboriginal population is an urban one. While there is a growing amount of material available about Aboriginal experiences and histories generally, there is very little public knowledge about how Aboriginal people define their cultural identities in cities. Misinterpretations of the nature of Aboriginal identities create a poor basis for formulating public policy. Early perspectives that discussed urban Aboriginal people only in terms of their cultural distinctness or only in terms of their socio-economic status, for example, led to inadequate policy initiatives that focused only on assimilation and upward mobility without acknowledging cultural distinction and the impacts of racism and colonial domination, or only on the recognition of cultural distinctness without addressing socio-economic issues (Culhane 2009). Better information about the nature of contemporary urban Aboriginal identities is an essential facet of understanding how contemporary cities with increasingly large Aboriginal populations work economically and socially. For governments, the research on urban Aboriginal identities provides insights into appropriate definitions of urban Aboriginal self-government, representation, and program definition; processes contributing to recent population increases; and factors that support or erode Aboriginal identities in cities. $(2011,80)$

While this may be important, and though the work of responsible academics such as Peters, Ray and others mentioned throughout this research continue to play a vital role in the enhancement of Métis peoples in Canada, there must equally be raised the words of caution as spoken by Chris Anderson (2011) and others. If self-identification is to be the standard by which data is collected, then its products must be used accordingly. As the nation state has shown historically it is more probable that to manage its political purposes and at the same time deal with Métis rights and associated socio-economic needs of Métis, it will use data in a manner that speaks to its agenda. 


\section{Chapter: Conclusion}

This research sought to explore the concepts of identity, Métis identity, the application of Métis identity in the response to the Supreme Court of Canada 2006 Powley decision and finally the use of census data to determine the probable existence of Métis communities that would meet one of the requirements set in the Powley decision to determine Métis Aboriginal rights. While each of these components could be treated as unique research opportunities, combining them provided for what I hope was a better understanding of the issues surrounding Métis peoples asserting their Aboriginal rights and power to define their own identities that are recognized by the courts and other branches of the state.

This research shows first and foremost that there are no universal pan Métis definitions of Métis identity that would be acceptable to all political Métis organizations, the state (both federal and provincial governments) or by Métis peoples themselves. Further, the research points out the problematic of even attempting to arbitrarily define a people's identity especially where such a rich and diverse history exists amongst the various communities across the country. In trying to force a single universal definition the risk exists that some peoples will be left out while others, who may not see themselves as falling under the definition, may be forced to accept an identity label which they themselves reject.

Throughout this research two considerations were at the forefront of the thesis question. The first was related to positionality in working on a subject matter that had a profound impact on people who have been marginalized throughout the history of Canada. I am not Métis and therefore had a social and ethical responsibility to be respectful of both the 
histories of Métis and the contemporary situations of Métis peoples not only as a researcher but also as someone who wanted to honor self-understandings of what it is to be Métis. The second was a belief that I had prior to starting this research that Métis existed throughout the country albeit with unique histories and identities. For me, the Métis, as I began work on this research, were the people who were Aboriginal but not Indian (First Nation) or Inuit. This latter position or belief was confronted in 2013 following an encounter with Jean Taillet, who was the lead legal counsel for the Powleys and a number of other highly important Métis rights cases, as well as being the great grandniece of Louis Riel. The thrust of her argument upon hearing of my research and my initial observations as I completed my first draft, was that Métis could only exist as part of the historic Métis Nation and nowhere else (although she did accept the argument that the NWTMN while distinct from the historic Métis Nation would also be recognized as Métis). This has been her publically held view and can be found in the "Métis Law Summary" publications which she has authored since 1999. This encounter changed my perception of the issue and thus created a significant departure from the work done to that date. Some ambiguity may exist in these pages because throughout the time of conducting the research and its writing, it has become clear that while trying to define Métis identity especially through use of quantitative tools such as the census, the subjective nature of the topic prevents a complete separation of the researcher's viewpoints from the final conclusion.

To be clear, the change in the approach I have taken is from a quantitative and objective quest to show Métis identity and communities as either existing or not existing to satisfy the needs of a court decision, to one that recognizes that identity cannot be managed and manipulated by numbers alone. The quest for a single Métis identity definition and a quantitative process to determine Métis communities may not be appropriate or possible to 
accomplish. But that does not mean that data, and especially the Census of Population, has no value in providing guidance. It only means that I no longer can take the position that quantitative research alone is an approach that should be taken by the courts or policy makers in looking at the rich and diverse subject of Aboriginal peoples who have been lumped together into a common Métis identity without thought or respect to unique and distinct identities.

In retracing this new way of focusing the research, Chapter 2 first aimed at arriving at an understanding of the approaches to take in recognizing the complex notion of identity and especially the ideas related to identity in a post (or neo) colonialist environment. Under the watchful gaze of Edward Said and other post colonialist writers the way identity is looked at through the eyes of the 'other' was the focus. This was followed by analysis of definitions used by different organizations in defining a membership under a common Métis identity. As the chapter explains, no single definition could be applied universally to all peoples who identify as Métis, nor could one political organization determined to define this identity actually achieve a consensus in a definition which would be acceptable to all organizations actively searching to define who Métis are. Finally the chapter also hesitatingly attempted to provide an overview of the history of Métis but as history and identity are tied this could only be done with consideration for separate Métis communities.

Chapter 3 synthesized a number of Métis court cases which have been significant in approaching the topic of Métis identity within the court rulings related to Métis rights. The legal cases examined have played a significant role in how policy makers have evolved the legislative framework that defines the relationship the state has with Aboriginal people. The cases also show how the question of identity can be removed from those claiming that 
identity and placed in the hands of a small group of elites, often with their own biases providing the basis for a decision.

The courts' use of expert witnesses was also seen in Chapter 3 and the role they play in determining Métis identity. It may be that a Western or Eurocentric bias is somewhat drawing to a close, or at the very least is being offset by research conducted by academics whose positions better align with Aboriginal interpretations of their own histories. The Federal Court of Canada's recent decision in CAP-Daniels is a case in point. One of the Crown's expert witnesses, Professor Alexander von Gernet, who has appeared before the courts on numerous occasions almost exclusively in support of the Crowns assertions, was chastised by the courts for his approach which the court viewed as being his own opinions. The court went on to state,

[179] Von Gernet's evidence suffered from a number of other problems. He relied on a database of documents provided by the Defendants which was not current or updated. He relied extensively on secondary sources which became clear when he did not understand the context in which much of that material arose. His conclusions were often based on faulty understanding; for example, the frailties of the 1871 Census as a reliable indicator of "Indian/half-breed" population...

[181] Unfortunately, von Gernet exhibited a shallow understanding of many of the documents he relied upon or was unexplainably selective in his use of evidence. Thus, his evidence stood in sharp contrast to many of the other witnesses on both sides in terms of knowledge, reliability and credibility. (Daniels v. Canada (3013 FC6) T-2172-99)

It is clear that Canadian courts are expecting more from expert witnesses which in turn offers exciting opportunities for geographers to be engaged to help tell the histories of Aboriginal peoples, including those of the Métis, in this sometimes confusing and often confrontational environment. 
In his 2005 federal court ruling, Justice Teitelbaum wrote,

"I have attempted to present, for the most part, an historical chronology, as opposed to drifting into any analytical abstractions, which is best left for academics, not judges" (Samson Indian Nation and Band v. Canada, 2005 FC 1622. At para 3).

It is important to note that had the 'analytical abstractionisms' that Justice Teitelbaum speaks to in his decisions been truly left to academics, of whom I will specify as being mainly historians and geographers, to guide courts in their interpretation of the historical and spatial realities of Aboriginal peoples, then Canadian jurisprudence would not have propagated the over 400 years of neo-colonial thinking that has dictated Aboriginal realities in Canada. Unfortunately Canadian courts have their own brand of 'analytical abstractionism' which has been laced with their own bias towards the interpretation of Canadian history vis a vis Aboriginal peoples. This same view has been put forward by scholars such as Nicholas K. Blomley (1994) and Arthur Ray (1990). With respect to how it does this Blomley writes,

When law does turn to social science, including geography, it tries to do so on its own terms, admitting social science 'facts' or 'opinions' only as inputs into a doctrinally centered interpretive process (Blomley, 1994; 4).

For geographers then it is important to express our desire to play a role within the legal discourse as it applies to spatial and temporal issues while at the same time recognizing the legal system's inherent prejudices.

Geography has had a history of not always knowing where it fits (Aitken and Valentine, 2006; Holt-Jensen, 2004; Johnston and Sidaway, 1979; Livingstone, 1992; Stoddart, 1986). What is relevant with respect to this thesis, is the role geography, and more specifically the sub field of cultural geography, may play in providing expert testimony to the courts. Geographers have leant their academic expertise to the courts in Canada. Professor Arthur 
J. Ray was involved as an expert witness on Aboriginal rights cases since 1985, as an expert in Aboriginal history both pre and post contact (Ray, 2011: 3) and his thoughtful contribution has shown the relevant role geography can make.

In this research, I have shown that the definition of Métis communities is the Western bias in the interpretation of history by the Supreme Court of Canada when making decisions that affect the very existence of Métis peoples since the concepts of community do not consider concepts of oral traditions or traditional territory as sole justifications for rendering a positive decision in favor of an Aboriginal claimant. While a number of expert witnesses in the court cases, such as Dr. Arthur Ray and Dr. Frank Tough, provided clear support for using an Indigenous frame of reference to understand the issues of history, identity and relation to place, the court has consistently relied on the more Eurocentric approach.

Finally the research moved into an attempt to use quantitative methodology to provide an opportunity to distinguish Métis communities from the general population using the Census of population data in Chapter 4.

There has not been enough critical discussion in the academic community on the use census data for research. Geographers such as Professor Evelyn J. Peters $(2000 ; 2001)$ have used census data effectively to provide a synthesis of information pertaining to Canadian Aboriginals in urban areas. But even for Professor Peters, there remains a disconnect between those countries that recognize their Indigenous populations and how those 
countries enumerate the Indigenous populations with tools such as a census of the population. She writes,

despite the large number of countries that endorsed the Declaration, relatively few enumerated their Indigenous residents. As a result, many Indigenous peoples remain invisible, and the implications of their histories of marginalization and exclusion are not often publicly documented in census statistics. Where questionnaires did enumerate Indigenous peoples, they often homogenized different cultures and Indigenous identities, failing to recognize the distinctive lifeways that different Indigenous peoples create in contemporary society. In many census questionnaires, Indigenous peoples were categorized as minorities, sweeping aside their unique rights and providing a basis for states to sidestep their responsibilities for safeguarding these rights. As a result, overwhelming challenges face the United Nations, various governmental and non-governmental organizations, and Indigenous people themselves in their attempts to document the circumstances of Indigenous populations and meet some of the information-related aims of the UNPFII (Peters, 2011: 85)

Peters is highlighting the issue of how the state applies its power over Indigenous populations. Without consistent and sound data, how can the state truly follow through with commitments made in declarations such as the UN Declaration on the Rights of Indigenous Persons, signed by most member nations in $2008 ?$

In addition to the views by some scholars on the relative importance of data gathering such as that of the census, other scholars are highly critical of what they see as a method of control by the state. The term Métis, according to some, has led to the 'racialization of Métis in the Canadian census' (Anderson, 2008) due to the definitional shift from considering the Métis as a nation to one that is an Aboriginal population. On this Anderson states:

Although perhaps scholarly in their own right, these explanations are nevertheless troubling for their failure to problematise the underlying, colonially inscribed premise grounding their analysis: namely, that such a thing as a singular, homogenous 'Métis population' exists at all. (Anderson, 2008: 348) 
This, looked at in one grand picture then, seems to indicate that like the term Métis, the term Aboriginal may be a term used from a position of power to limit, redefine, and possibly destroy the identity of many nations and peoples into one neatly packaged group that then has to appear before the courts with some form of unified history to argue its universal rights.

\section{A Final Thought}

Both the constitutional definition, and following from this, the national census, create an opportunity for Aboriginal self-identification that has influenced the way people see the term Métis. As I have argued throughout this research, whereas people of mixed Aboriginal and non-Aboriginal ancestry may use the term Métis as an identity, being Métis is influenced more by a nationalistic sense of self as a part of a specific community. Looked at another way, being Métis is centered on a sense of pride in one's identity as distinct from the larger Canadian population, a sense of difference from others, not dissimilar from the notion of being part of a "distinct society" held by many Quebecois, who see themselves as different from their provincial neighbors.

Indigenous peoples of mixed Aboriginal and non-Aboriginal ancestry need to be provided the opportunity to identify themselves as they see fit and not be bound by the nation state's limitations in language that can be seen with the current Census of Canada identity question, a limitation created by an ambiguous and politically influenced application of the identity of Métis to all people of mixed ancestry. A new way of working with these communities must also be considered by the government that follows through on its commitments made in 1982 at the repatriation of the constitution that truly recognizes that,

"The existing Aboriginal and treaty rights of the Aboriginal peoples of Canada are hereby 
recognized and affirmed."(Constitution Act 1983, s35). Who the Aboriginal peoples of Canada are must be reopened to accept and acknowledge all Aboriginal communities not just those that fit within the narrow definitions of the Constitution Act as well as accept a more universal application of a people may not exist within the current legislative framework. Only then will Canada truly recognize all Aboriginal peoples. 
ILLUSTRATIONS 
Map 1 - 2006 Winnipeg CTs

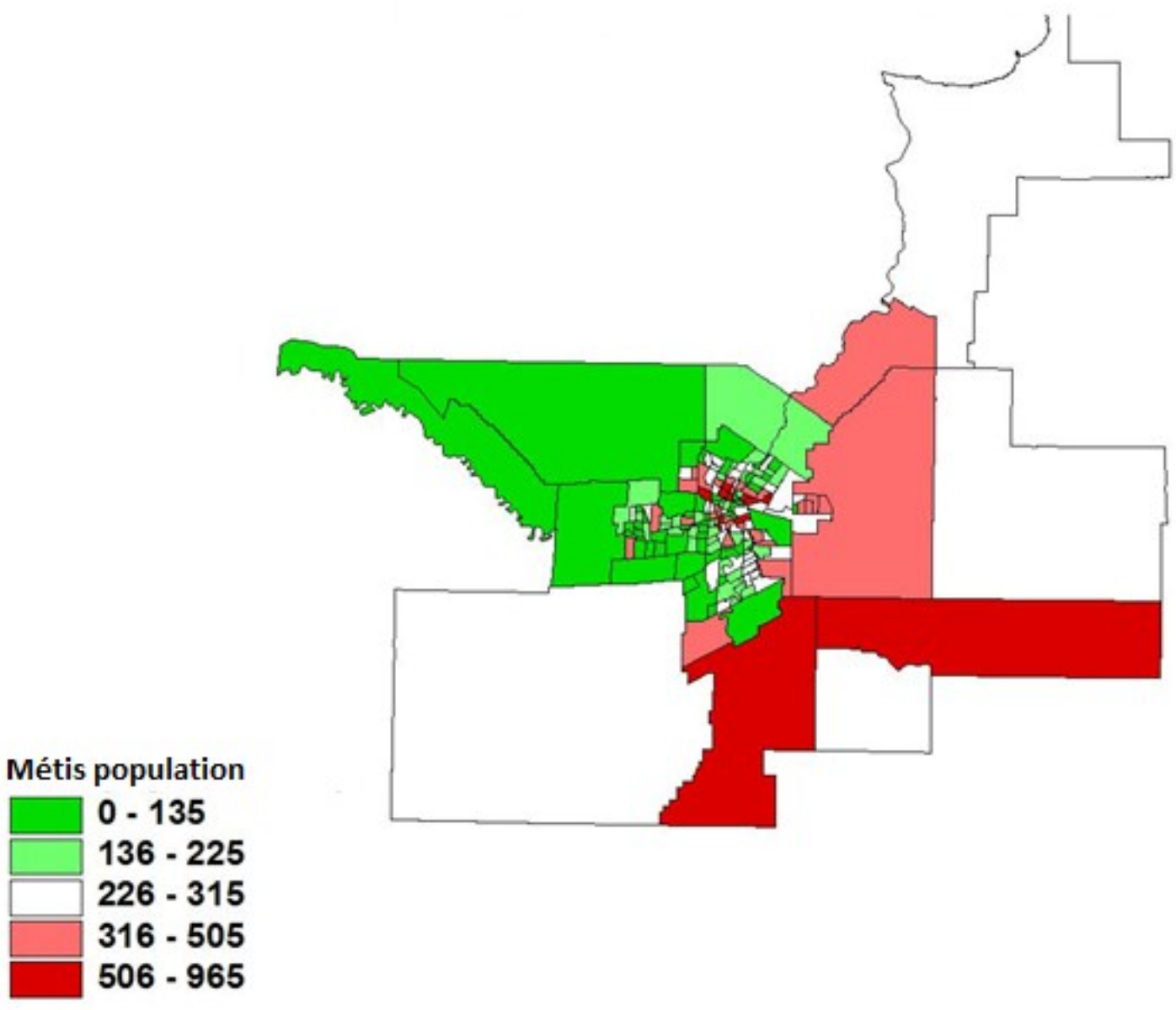


Map 2 - 2006 CSD Métis identity - Hot Spots

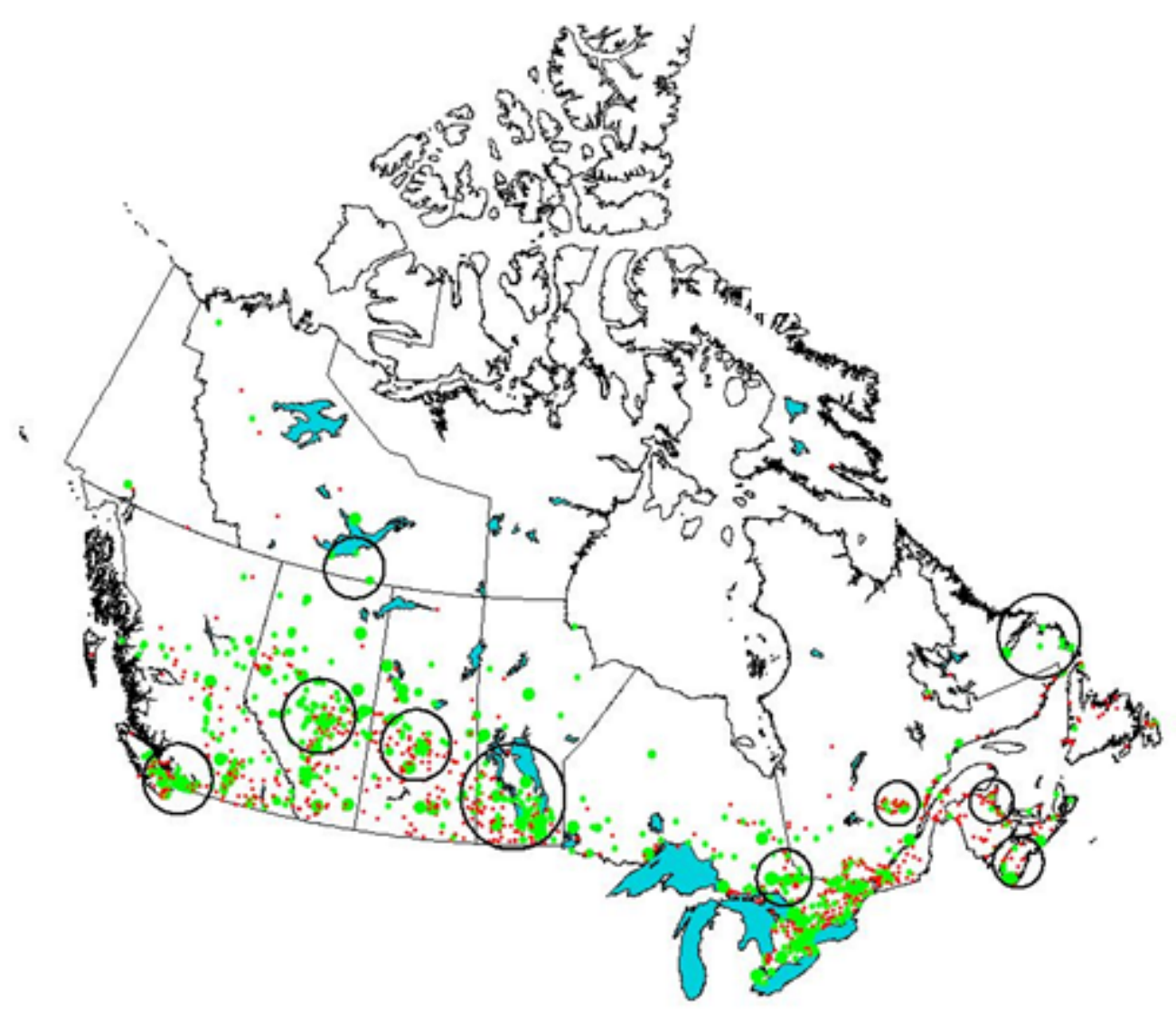


Map 3 - 2006 CSD Métis population normalized by total population - Hot Spots

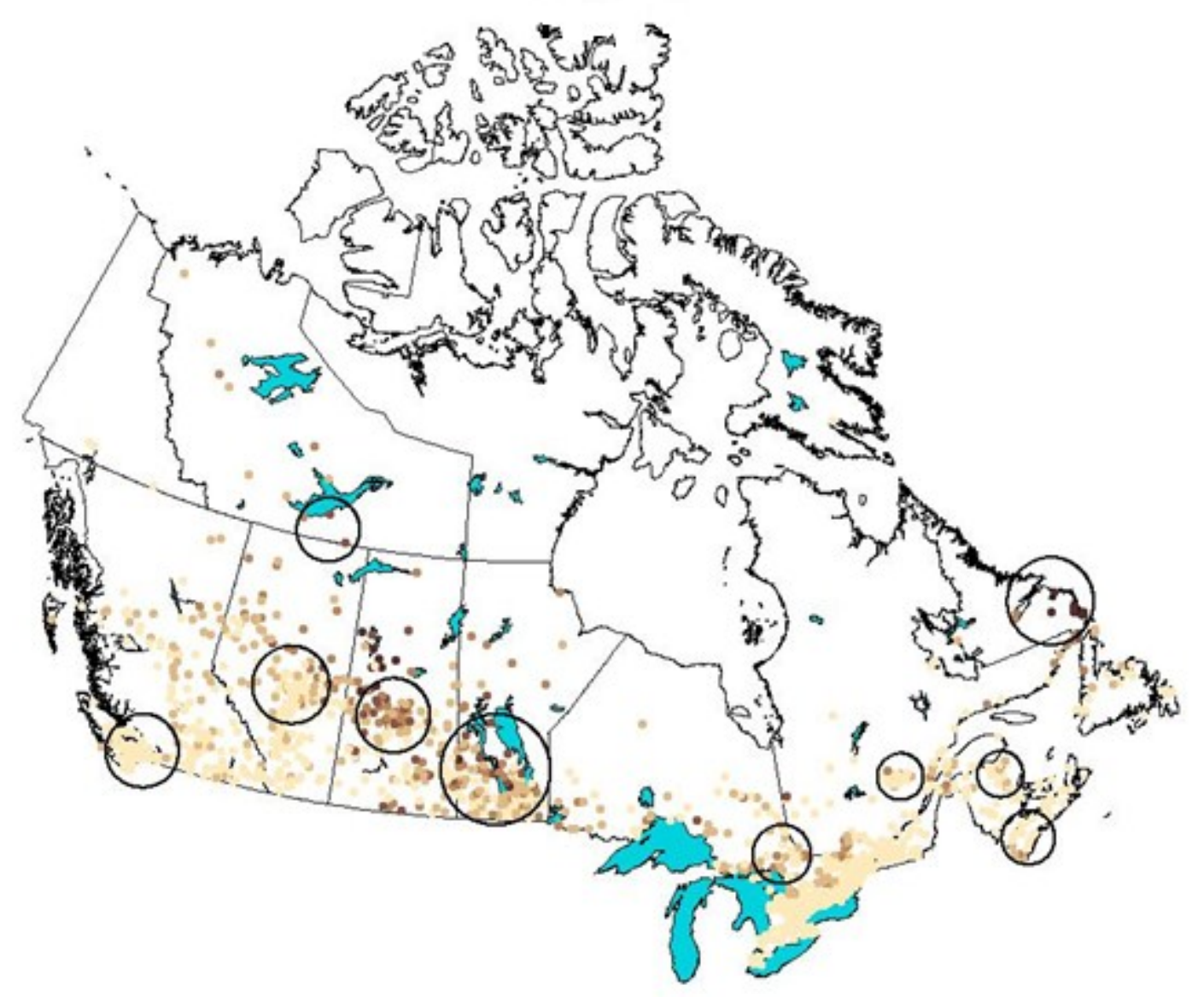




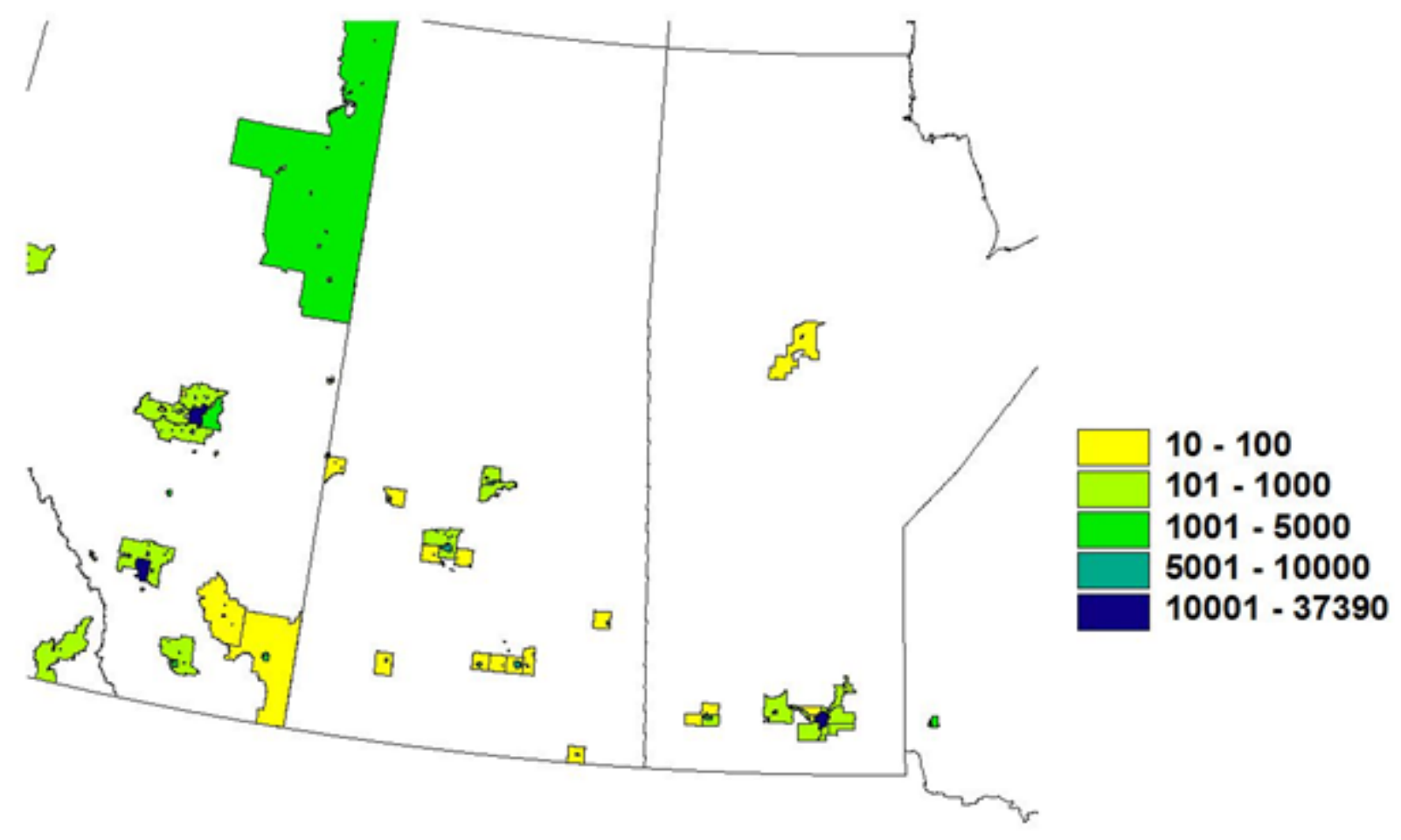


Map 5-2006 CSD Métis as percentage of total population

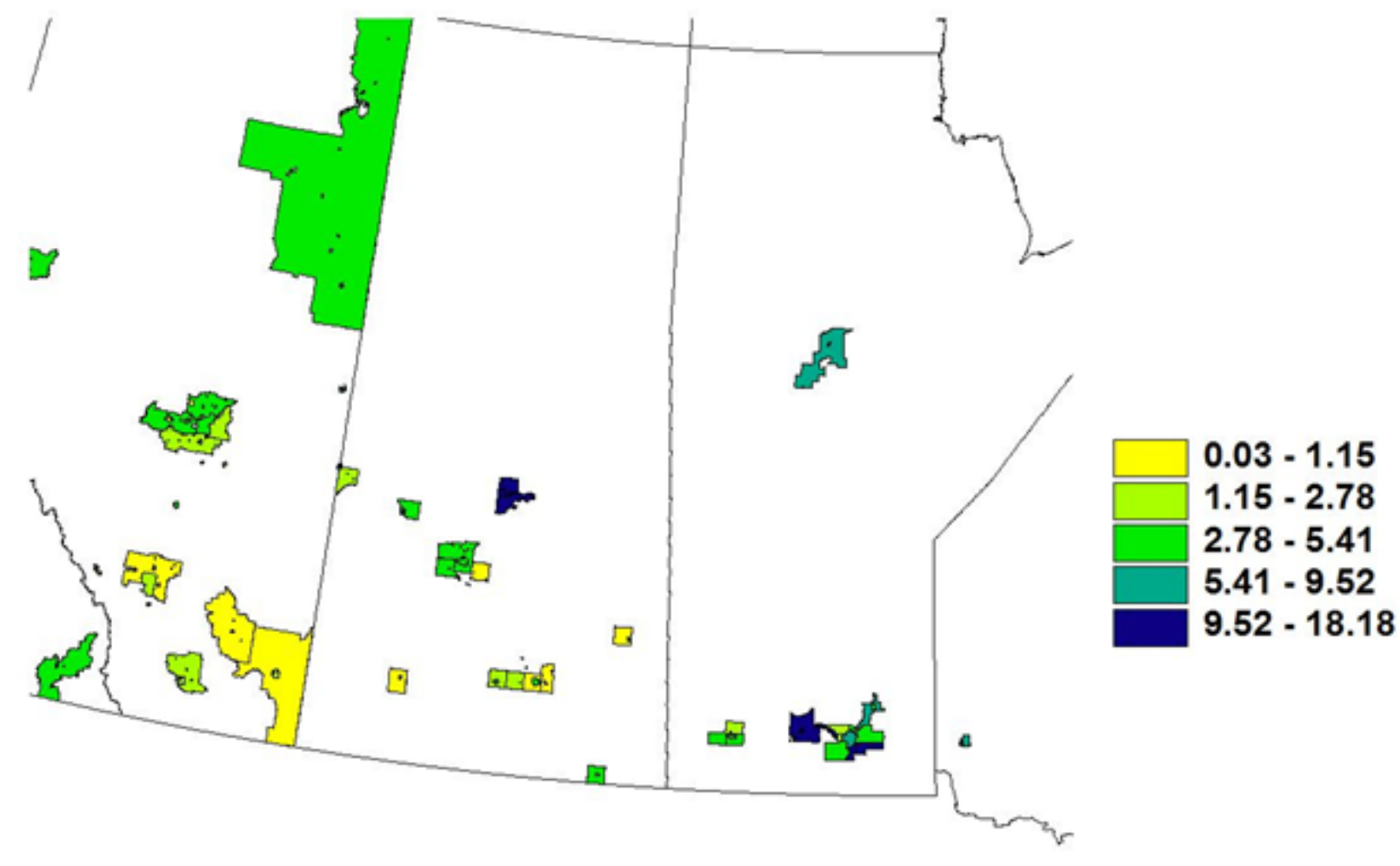


Map 6 - 2006 CSD Métis as percentage of Aboriginal population

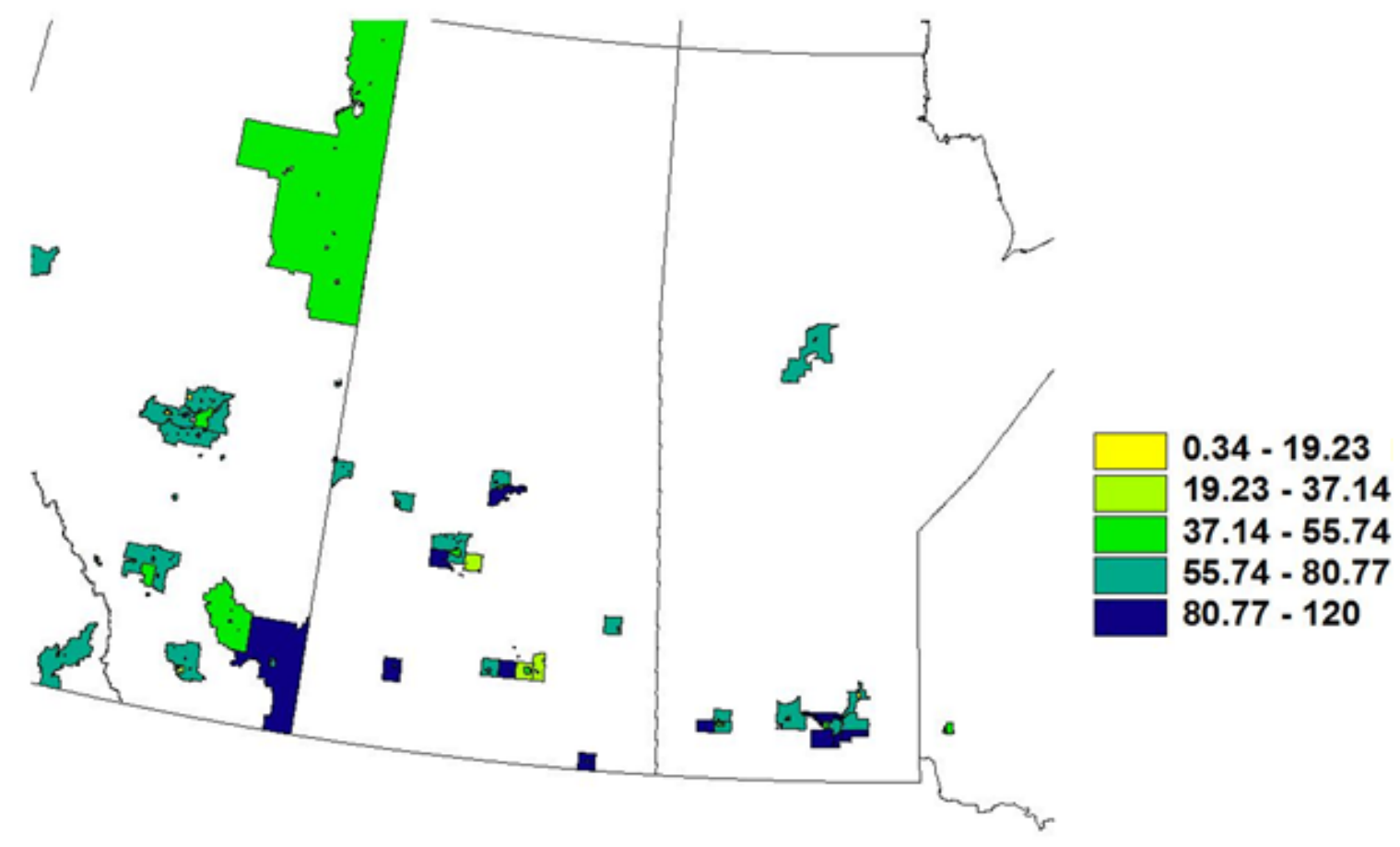


Map 7 - North Bay area Métis Communities

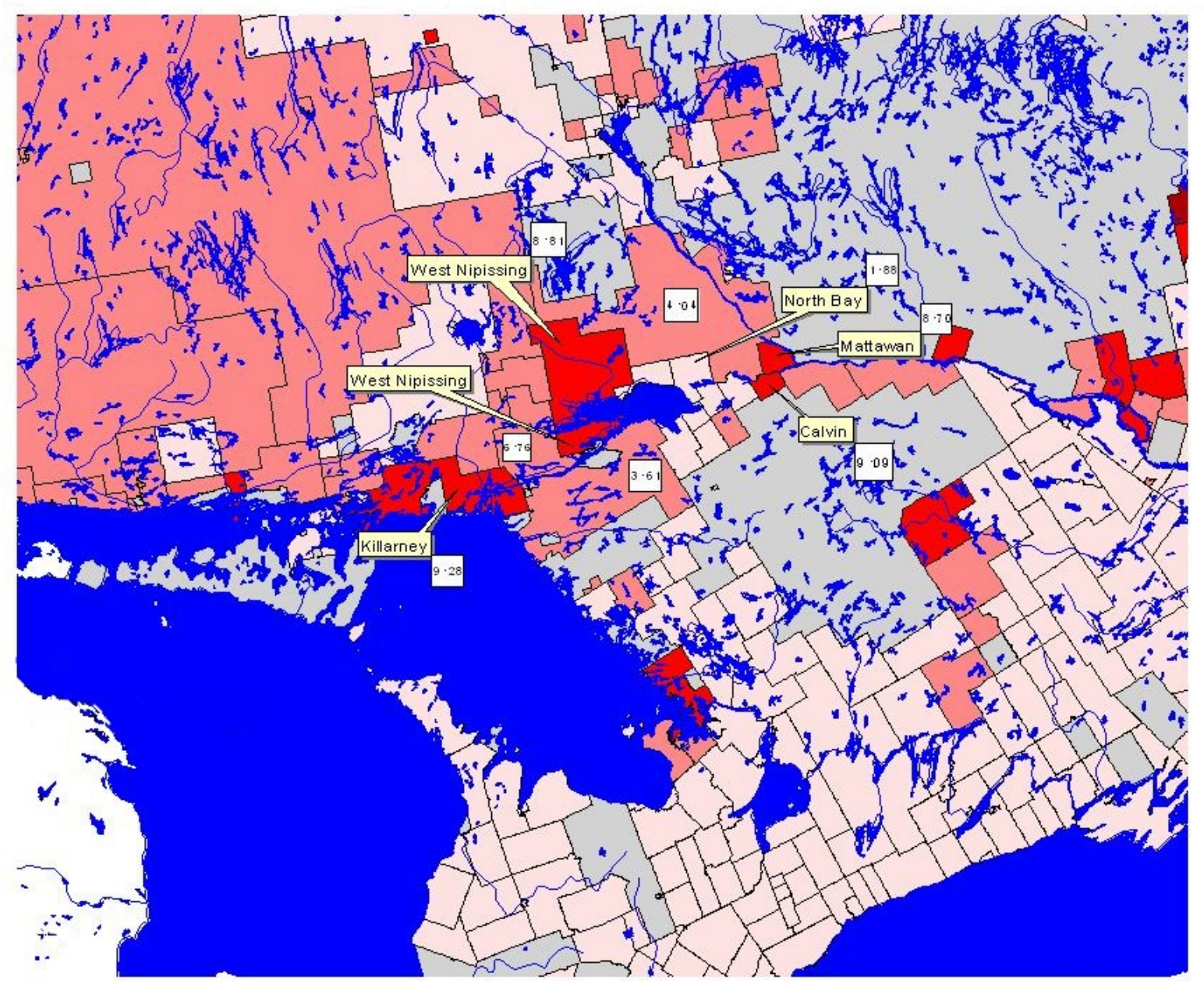




\section{Bibliography or References}

Adams, Christopher, Ian Peach, and Gregg Dahl. (2013)Métis in Canada : History, Identity, Law \& Politics. Edmonton: University of Alberta Press.

Adams, Howard.(1994) A Tortured People; the Politics of Colonization. Penticton, B.C: Theytus Books.

Alfred, Taiaiake (1999) Peace Power Righteousness: an Indigenous manifesto. Don, Mills: Oxford University Press.

Alfred, Taiaiake (2005) Wasase: Indigenous pathways of action and freedom. Peterborough, Ontario: Broadview Press.

Andersen, Chris. (2008). From Nation to Population: The Racialisation of 'Métis' in the Canadian Census. Nations and Nationalism 14(2), 347-368.

Andersen, Chris. (2011). I'm Métis, What's your excuse?: On the optics and the Ethics of the Misrecognition of Métis in Canada. Aboriginal Policy Studies 1(2), 161-165

Anderson, Chris. (2014) Métis: Race, Recognition, and the Struggle for Indigenous Peoplehood. Vancouver: UBC Press.

Alberta, Province of. (2006) Report of the MLA Committee on Métis Harvesting.

Barber, Katherine (2004) Canadian Oxford Dictionary. Toronto: Oxford University Press.

Barkwell, Lawrence J., Leah Dorion and Darren R. Préfontaine. (1999) Resources for Métis Researchers. Winnipeg and Saskatoon: Co-published by Gabriel Dumont Institute of native Studies and Applied Research and The Louis Riel Institute of the Manitoba Métis Federation.

Battiste, Marie and James (Sa'ke'j) Youngblood Henderson (2002) Protecting Indigenous Knowledge and Heritage: A Global Challenge. Saskatoon, Sakatchewan. Purich Publishing. 
Bhabha, Homi K. (2007) The Location of Culture. New York, London: Routledge.

Binnema, Theodore, Gerhard John Ens, R. C. Macleod, and John Elgin Foster (Eds.) (2001). From Rupert's Land to Canada. Edmonton: University of Alberta Press.

Block, Peter. (2008) Community the Structure of Belonging. San Francisco, Calif: BerrettKoehler Publishers.

Boisvert, David and Keith Turnbull. (1985) Who are the Métis? Studies in Political Economy 18: 107-148

Borlase, Tim. (1994) The Labrador settlers, Métis and Kablunangajuit. Happy ValleyGoose Bay, NFLD: Labrador East Integrated School Board.

Bouchard, Russel. (2006) La longue marche du Peuple oublié...Ethnogenèse et spectre culturel du Peuple Métis de la Boréalie, Saguenay:Chik8timitch.

Bourrie, Mark. (1998) RIGHTS-CANADA : Indigenous People Tell Mandella of Their Plight. Web site http://www.ipsnews.net/1998/09/rights-canada-indigenous-peopletell-mandela-of-their-plight/. Accessed January 1, 2015

Cadena, Marisol de la, and Orin Starn. (2007) Indigenous Experience Today. New York: Oxford.

Canada. (1996) Royal Commission on Aboriginal Peoples, Georges Erasmus, and Rene Dussault. Report of the Royal Commission on Aboriginal Peoples. Ottawa

Canada. (2013) Report of the Standing Senate Committee on Aboriginal Peoples. Vernon White and Lillian Eva Dyck. "The People Who Own Themselves": Recognition of Métis Identity in Canada. Ottawa

Casey, Edward S. (1993) Getting Back into Place: Toward a Renewed Understanding of the Place-World. Bloomington and Indianapolis: Indiana University Press

Casey, Edward S. (1997) The Fate of Place: A Philosophical History. Berkeley: University of California Press.

Chartrand, Paul L. A. H. (2002) Who are Canada's Aboriginal Peoples? : Recognition, Definition and Jurisdiction. Saskatoon: Purich Pub. 
Chartrand, Paul L. A. H. (2002) Introduction. In Paul L.A.H. Chartrand (Ed) Who are Canada's Aboriginal Peoples?: Recognition, Definition and Jurisdiction. (15-26) Saskatoon: Purich Pub.

Chartrand, Paul L. A. H. (2002) Background. In Paul L.A.H. Chartrand (Ed) Who are Canada's Aboriginal Peoples?: Recognition, Definition and Jurisdiction. (27-40) Saskatoon: Purich Pub.

Cherubini, Lorenzo. (2008) Aboriginal Identity, Misrepresentation, and Dependence: A Survey of the Literature. The Canadian Journal of Native Studies 2: 221-239.

Deloria, Vine. (2010) God is Red: A Native View of Religion. Golden, Colerado: Fulcrum Publishing

Friesen, John W. and Virginia Lyons Friesen. (2004) We are included! : the Métis people of Canada realize Riel's vision. Calgary: Detselig Enterprises.

Giokas, John and Paul L. A. H. Chartrand (2002) Who are the Métis in Section 35? A Review of the Law and Policy Relating to Métis and "Mixed-Blood" People in Canada. In Paul L.A.H. Chartrand (Ed) Who are Canada's Aboriginal Peoples?: Recognition, Definition and Jurisdiction. (83-125) Saskatoon: Purich Pub.

Gionet, Linda. (2009)“Métis in Canada; Selected findings of the 2006 Census." Canadian Social Trends 87: 22-26.

Giraud, Marcel. (1945) Le Mâetis Canadien, Son Rãole Dans l'Histoire Des Provinces De l'Ouest. Paris: Institut d'ethnologie.

Goulet, George and Terry Goulet (2008) The Métis: Memorable Events and Memorable Personalities. Clagary: FabJob Inc.

Guimond, Eric. (2003) Changing Ethnicity: The Concept of Ethnic Drifters. In Jerry Patrick White, Paul S. Maxim, and Daniel J. K. Beavon (Eds.). Aboriginal Conditions: Research as a Foundation for Public Policy. (pp. 91-107) Vancouver: UBC Press.

Guimond, Eric, Don Kerr and Roderic Beaujot. (2004) Charting the Growth of Canada's Aboriginal Populations: Problems, Options and Implications. Canadian Studies in Population 31(1): 55-82. 
Gusfield, Joseph R. (1975) Community: A Critical Response. Oxford: Blackwell.

Harvey, David (1969) Explanation in Geography. London: Edward Arnold Ltd.

Heidegger, Martin (2010) Being and Time. Translated by Joan Stambaugh. Albany, New York: State University of New York.

Hubner, Brian Edward. (2007) 'This is the Whiteman's Law': Aboriginal resistance, bureaucratic change and the Census of Canada, 1830-2006. Archival Science 7(3): 195-206.

Innis, Harold A. (1930) The Fur Trade in Canada: An Introduction to Canadian Economic History. New Haven: Yale University Press.

Isaac, Thomas. (2012) Aboriginal Law: Commentary and Analysis. Saskatoon, Saskatchewan: Purich Publishing.

Isin, Engin F. (Engin Fahri), and Patricia K. Wood. (1999) Citizenship and Identity. London ; Thousand Oaks, Calif: Sage.

Jantzen, Lorna. (2004) Reporting Métis in Urban Centres n the 1996 Census In Jerry Patrick White, Paul S. Maxim, and Daniel J. K. Beavon (Eds.). Aboriginal Policy Research: Setting the Agenda for Change Volume 1(pp. 85-112) Toronto: Thompson Educational Publishing, Inc.

Kumar, Mohan B. and Teresa Janz (2010) An exploration of cultural activities of Métis in Canada. Canadian Social Trends. 63-67

Lawrence, Bonita (2003) Gender, Race, and the Regulation of Native Identity in Canada and the United States: An Overview. Hypatia. 18(2). 3-31.

Liu, James H. and Janos László (2007) A narrative theory of history and identity: Social identity, social representations, society and the individual. In: G. Moloney, Iain Walker (eds.): Social representations and history. Palgrave-Macmillan, 85-107.

Lussier, Antoine S. (1985) Aspects of Canadian Métis History. Research Branch. Corporate Policy. Indian and Northern Affairs Canada. 
Lussier, Antoine S., D. Bruce Sealey, and Ted J. Brasser. (1978) The Other Natives, the Métis. Winnipeg: Manitoba Métis Federation Press : Editions Bois-Brules. Volumes 1,2 , and 3 .

McMillan, David W. and David M. Chavis George. (1986) "Sense of Community:A Definition and Theory." Journal of Community Psychology 14: 6-16.

Morton, Arthur Silver. (1973) History of the Canadian West to 1870-71. Toronto: Nelson. Normand, Josée.(1996) A Profile of the Métis: Target Groups Project. Statistics Canada: Housing, Family and Social Statistics Division. Minister of Industry.

Peet, Richard (2001) Modern Geographical Thought. Malden, Massachusetts: Blackwell Publishers.

Peters, Evelyn (2000). Aboriginal people and Canadian geography: a review of the recent literature. (44-55) The Canadian Geographer. 44(1).

Peters, Evelyn (2001). Geographies of Aboriginal people in Canada. (138-144) The Canadian Geographer. 45(1).

Peters, Evelyn. (2011) Emerging Themes in Academic Research in Urban Aboriginal Identities in Canada, 1996-2010. Aboriginal Policy Studies 1(1): 78-105.

Peters, Evelyn (2011). Still Invisible: Enumeration of Indigenous Peoples in Census Questionnaires Internationally. (68-100) Aboriginal Policy Studies. 1(2).

Peterson, Jacqueline Louise, and Jennifer S. H. Brown (1985). Introduction. In Jacqueline Louise Peterson and Jennifer S. H. Brown (Eds.), The New Peoples : Being and Becoming Métis in North America. (pp. 3-16) Winnipeg: University of Manitoba Press.

Peterson, Jacqueline Louise, and Jennifer S. H. Brown. (1985) The New Peoples : Being and Becoming Métis in North America. [Winnipeg]: University of Manitoba Press.

Podruchny, Carolyn. (2006) Making the Voyageur World : Travelers and Traders in the North American Fur Trade. Toronto: University of Toronto Press. 
Podruchny, Carolyn, Nicole St-Onge, and Brenda Macdougall. (2012) Contours of a People : Métis Family, Mobility, and History. Norman: University of Oklahoma Press.

Raagma, Garri. (2003). Centre-Periphery Model Explaining the Regional Development of the Informal and Transitional Society. Communication presented at the $43^{\text {rd }}$ Congress of the European Regional Science Association, Jyvaskyla, Finland.

Ray, Arthur J. (2005) Indians in the Fur Tade. Toronto: University of Toronto Press.

Ray, Arthur J. (2011) Telling it to the Judge: Taking Native History to Court. Montreal: McGill-Queen's University Press.

Richardson, Cathy. (2006) "Métis Identity Creation and Tactical Responses to Opression and Racism." Variegations 2: 56-71.

Roosens, Eugeen E. (1989). Creating Ethnicity: the process of ethnogenesis, London: Sage Publications

Said, Edward W. (1979) Orientalism. New York: Random House.

Saku, James C. (1999) Aboriginal Census Data in Canada: A Research Note." The Canadian Journal of Native Studies XIX, no. 2: 365-379.

Sanders, D. (1979), Métis Rights in the Prairie Provinces and the Northwest Territories: A Legal Interpretation. In: The Forgotten People: Métis and Non-Status Indian Land Claims, edited by Harry W. Daniels, Ottawa: Aboriginal Council of Canada, pp. 522.

Sawchuk, Joe. (1992) "The Métis, Non-Status Indians and the New Aboriginality: Government Influence on Native Political Alliances and Identity" in Readings in Aboriginal Studies Volume 2. Brandon, Manitoba. Bearpaw Publishing, 1992.

Sawchuk, Joe. (2001) "Negotiating an Identity: Métis Political Organizations, the Canadian Government, and Competing Concepts of Aboriginality." The American Indian Quarterly 25(1): 73-92.

Siggner, Andy, Jeremy Hull, Annette Vermaeten, Eric Guimond and Lorna Jantzen. (2001).Understanding Aboriginal Definitions: Implications for Counts and SocioEconomic Characteristics. Communication presented at the annual meeting of the Canadian Population Society, Université Laval, Quebec. 
Slobodin, Richard. (1966) Métis of the Mackenzie District. Ottawa : Canadian Research Centre for Anthropology, Saint-Paul University.

Smith, Linda Tuhiwai. (2005) Decolonizing Methodologies: Research and Indigenous Peoples. London and New York: Zed Books.

Stanley, George F. G. (1992) The Birth of Western Canada: A History of the Riel Rebellions. Toronto: University of Toronto Press,

Statistics Canada (2012) Census Dictionary. Ottawa, Minister of Industry

Sturm, Circe Dawn. (2002) Blood Politics: Race, Culture, and Identity in the Cherokee Nation of Oklahoma. Berkeley and Los Angeles: University of California Press.

Sultana, Farhana. (2007). Reflexivity, Positionality and Participatory Ethics: Negotiating Fieldwork Dilemmas in International Research. ACME:An International E-Journal for Critical Geographies . 6(3), 374-385

Surette, Roland F. (2004) Métis/Acadien Heritage 1604 to 2004. Lower Wedgeport, Nova Scotia: Sentinel Printing Inc.

Teillet, Jean (2006) Métis Law in Canada. Vancouver: Pape Salter Teillet.

Teillet, Jean (2012) The Métis and Thirty Years of Section 35: How Constitutional Protection for Métis Rights has Led to the Loss of the Rule of Law. Supreme Court Law Review (2012), 58 S.C.L.R (2d)

Teillet, Jean and Jason Madden (2009) R.v.Goodon: Manitoba Provincial Court Confirms Métis Harvesting Rights. Winnipeg, Manitoba: Manitoba Métis Federation.

Turner, Dale A. (2006). This is Not a Peace Pipe : Towards Critical Indigenous Philosophy. Toronto: University of Toronto Press.

Weaver, Hilary N. (2001) "Indigenous Identity: What is it, and Who really has it?" American Indian Quarterly 25(2): 240-255. 
White, Jerry Patrick and Paul S. Maxim (2003) Social Capital, Social Cohesion, and Population Outcomes in Canada's First Nation Communities. In Jerry Patrick White, Paul S. Maxim, and Daniel J. K. Beavon (Eds.). Aboriginal Conditions: Research as a Foundation for Public Policy. (pp. 7-33) Vancouver: UBC Press.

White, Jerry Patrick, Paul S. Maxim, and Daniel J. K. Beavon. (2003) Aboriginal Conditions : Research as a Foundation for Public Policy. Vancouver: UBC Press.

White, Jerry Patrick, Paul S. Maxim, and Daniel J. K. Beavon (Eds.) (2004) Aboriginal Policy Research: Setting the Agenda for Change Volume 1. Toronto: Thompson Educational Publishing, Inc.

Wilson, Frederica and Melanie Mallet, (2008) Métis-Crown Relations: Rights, Identity, Jurisdiction and Governance. Toronto: Irwin Law Inc.

Zimmerly, David William (1982) Cain's Land Revisited: Culture Change in Central Labrador, 1775-1972. St. John's: Memorial University. 


\section{Case $\mathrm{Law}^{4}$}

Badger, R. v.1996 CanLII 236 (S.C.C.), [1996] 1 S.C.R. 771

Baker, R. v., [2005] ONJC 38 (CanLII)

Beaudry, R. v. [2006] O.J. No. 790

Blais, R. v. (unreported, Ontario Court of Justice, May 2, 2013) "Blais (Ont)"13-Blais, R. v.[2003] SCC 44 (CanLII); 2001 MBCA 55 (CanLII); [1998] 4 CNLR 103 (QB); [1997] 3 CNLR 109 (PCt) "Blais (Mb)"

Calder et al. v. Attorney-General of British Columbia.[1973] CanLII 4 (SCC), [1973] SCR 313

Corbiere v. Canada (Minister of Indian and Northern Affairs) [1999] 2 S.C.R. 203 at 220.

Côté,R. v.[1996] 3 S.C.R. 139

Daigle, R. v. [2003] 3 C.N.L.R. 232 (N.B. Prov Crt); 2004 NBQB 79 (CanLII)

Daigle, R. v. [2003] NBPC 4 (CanLII)

Daniels v. Canada, 2013 FC 6 (F.C.T.D.) For decisions on motions see: 2002 FCT 295; 2005 FC 1109; 2011 FC 230 (CanLII).

Delgamuukw v. B.C.[1997] 3 SCR 1010; 1993 CanLII 4516 (BC CA); 1991 CanLII 2372 (BC SC)

Gladstone, R. v., [1996] CanLII 160 (SCC), [1996] 2 SCR 723

Goodon, R. v., [2008] MBPC 59 (CanLII)

\footnotetext{
${ }^{4}$ The cases listed here play a major role either directly in Métis law, such as Powley< Goodon and Blais, or indirectly applying more generally to all Aboriginal peoples in Canada such as Haida, Mikisew and Sparrow. This list is not exhaustive and is limited to the cases that find application in this research directly or indirectly by reference.
} 
Haida Nation v. B.C. (Minister of Forests)[2004] 3 S.C.R. 511; aff'g [2002] BCCA 147 (CanLII)

Hirsekorn, R.v., 2011 ABQB 682

Mikisew Cree First Nation v. Canada (Minister of Canadian Heritage),[2005] 3 S.C.R. 388

Newfoundland and Labrador v. Labrador Métis Nation 2007 NLCA 75

Pamajewon,R. v. [1996] 2 S.C.R. 821 (S.C.C.)

Powley, R. v. (2003) SCC 43; aff'g [2001] O.J. No. 607 (Ont. C.A.); aff'g [2000] O.J. No. 99 (Ont. S.C.J.); aff'g [1998] O.J. No. 5310 (P.Ct.)

Re Eskimos[1939] S.C.R. 104.

Sappier, R. v.; R. v. Gray, 2006 SCC 54, [2006] 2 S.C.R. 686

Smith's Landing First Nation v. Parks Canada Agency and the Fort Smith Métis Council, Federal Court docket \# T-10-11.13-9

Sparrow, R. v. [1990] 1 S.C.R. 1075 (S.C.C.)

Sundown, R. v.[1999] 1 S.C.R. 393, 1999 CanLII 673 (S.C.C.)

Taku River Tlingit First Nation v. Tulsequah Chief Mine Project [2000] B.C.J. No. 1301

B.C.S.C.); aff'd [2002] B.C.J. No. 155 (B.C.C.A.); rev'd [2004] 3 S.C.R. 550

Tsilhqot'in Nation $v$. British Columbia, 2014 SCC 44

Van der Peet, R. v.,[1996] CanLII 216 (SCC), [1996] 2 SCR 507

Vautour, R. v. 2010 NBPC 39.

Vautour, R. v.[2001] N.B.J. No. 494

William v. British Columbia2012 BCCA 285 


\section{Data}

2011 National Household Survey: Data Tables Aboriginal Ancestry (6), Single and Multiple Aboriginal Ancestry Responses (3), Age Groups (6) and Sex (3) for the Population in Private Households of Canada, Provinces, Territories, Census Metropolitan Areas and Census Agglomerations, 2011 National Household Survey http://www12.statcan.gc.ca/nhs-enm/2011/dp-pd/dt-td/Rpeng.cfm? $\mathrm{LANG}=\mathrm{E} \& A P A T H=3 \& D E T A I L=0 \& D I M=0 \& \mathrm{FL}=A \& F R E E=0 \& \mathrm{GC}=0 \&$ $\mathrm{GID}=0 \& \mathrm{GK}=0 \& \mathrm{GRP}=1 \& \mathrm{PID}=105402 \& \mathrm{PRID}=0 \& \mathrm{PTYPE}=105277 \& \mathrm{~S}=0 \& \mathrm{SHOW}$ $\underline{\mathrm{ALL}}=0 \& \mathrm{SUB}=0 \& \mathrm{Temporal}=2013 \& \mathrm{THEME}=94 \& \mathrm{VID}=0 \& \mathrm{VNAMEE}=\& \mathrm{VNAMEF}$ $=($ Accessed January 4, 2014)

2001 Census Aboriginal Population Profiles http://www12.statcan.ca/english/Profil01/AP01/Search/List/Page.cfm?Lang=E\&GeoCod $\underline{\mathrm{e}=10}($ Accessed January 4, 2014)

Statistics Canada. 2007. Newfoundland and Labrador (Code10) (table). Aboriginal Population Profile. 2006 Census. Statistics Canada Catalogue no. 92-594-XWE. Ottawa. $\quad$ Released January 15, 2008. http://www12.statcan.ca/census-recensement/2006/dp-pd/prof/9294/index.cfm?Lang=E(accessed January 4, 2014).

Statistics Canada. 2007. Prince Edward Island (Code11) (table). Aboriginal Population Profile. 2006 Census. Statistics Canada Catalogue no. 92-594-XWE. Ottawa. $\begin{array}{lll}\text { Released January } 2008 . & \text { 15, }\end{array}$ http://www12.statcan.ca/census-recensement/2006/dp-pd/prof/92594/index.cfm?Lang=E (accessed January 4, 2014).

Statistics Canada. 2007. Nova Scotia (Code12) (table). Aboriginal Population Profile. 2006 Census. Statistics Canada Catalogue no. 92-594-XWE. Ottawa. $\begin{array}{lll}\text { Released January } 2008 . & 15,\end{array}$ http://www12.statcan.ca/census-recensement/2006/dp-pd/prof/92594/index.cfm? Lang=E (accessed January 4, 2014).

Statistics Canada. 2007. New Brunswick (Code13) (table). Aboriginal Population Profile. 2006 Census. Statistics Canada Catalogue no. 92-594-XWE. Ottawa. Released January 15, 2008. http://www12.statcan.ca/census-recensement/2006/dp-pd/prof/92594/index.cfm?Lang=E (accessed January 4, 2014). 
Statistics Canada. 2007. Quebec (Code24) (table). Aboriginal Population Profile. 2006 Census. Statistics Canada Catalogue no. 92-594-XWE. Ottawa. Released January 15, 2008. http://www12.statcan.ca/census-recensement/2006/dp-pd/prof/92594/index.cfm?Lang=E (accessed January 4, 2014).

Statistics Canada. 2007. Ontario (Code35) (table). Aboriginal Population Profile. 2006 Census. Statistics Canada Catalogue no. 92-594-XWE. Ottawa. Released January 15, 2008. http://www12.statcan.ca/census-recensement/2006/dp-pd/prof/92594/index.cfm?Lang=E (accessed January 4, 2014).

Statistics Canada. 2007. Manitoba (Code46) (table). Aboriginal Population Profile. 2006 Census. Statistics Canada Catalogue no. 92-594-XWE. Ottawa. Released January 15, 2008. http://www12.statcan.ca/census-recensement/2006/dp-pd/prof/92594/index.cfm?Lang=E (accessed January 4, 2014).

Statistics Canada. 2007. Saskatchewan (Code47) (table). Aboriginal Population Profile. 2006 Census. Statistics Canada Catalogue no. 92-594-XWE. Ottawa. Released January 15, 2008. http://www12.statcan.ca/census-recensement/2006/dp-pd/prof/92594/index.cfm?Lang=E (accessed January 4, 2014).

Statistics Canada. 2007. Alberta (Code48) (table). Aboriginal Population Profile. 2006 Census. Statistics Canada Catalogue no. 92-594-XWE. Ottawa. Released January 15, 2008. http://www12.statcan.ca/census-recensement/2006/dp-pd/prof/92594/index.cfm?Lang=E (accessed January 4, 2014).

Statistics Canada. 2007. British Columbia (Code59) (table). Aboriginal Population Profile. 2006 Census. Statistics Canada Catalogue no. 92-594-XWE. Ottawa. Released January 15, 2008. http://www12.statcan.ca/census-recensement/2006/dp-pd/prof/92594/index.cfm?Lang=E (accessed January 4, 2014).

Statistics Canada. 2007. Yukon Territory (Code60) (table). Aboriginal Population Profile. 2006 Census. Statistics Canada Catalogue no. 92-594-XWE. Ottawa. Released January 15, 2008. http://www12.statcan.ca/census-recensement/2006/dp-pd/prof/92594/index.cfm?Lang=E (accessed January 4, 2014). 
Statistics Canada. 2007. Northwest Territories (Code61) (table). Aboriginal Population Profile. 2006 Census. Statistics Canada Catalogue no. 92-594-XWE. Ottawa. Released January 15, 2008. http://www12.statcan.ca/census-recensement/2006/dp-pd/prof/92594/index.cfm?Lang=E (accessed January 4, 2014).

Statistics Canada. 2007. Nunavut (Code62) (table). Aboriginal Population Profile. 2006 Census. Statistics Canada Catalogue no. 92-594-XWE. Ottawa. Released January 15, 2008.

http://www12.statcan.ca/census-recensement/2006/dp-pd/prof/92594/index.cfm?Lang=E (accessed January 4, 2014). 